\title{
Quantitative Collision Risk Assessment of a Fixed-Type Offshore Platform with an Offshore Supply Vessel
}

\author{
M.P. Mujeeb-Ahmed ${ }^{\mathrm{a}, \mathrm{b}}$ and Jeom Kee Paik ${ }^{\mathrm{a}, \mathrm{b}, \mathrm{c}, *}$ \\ a The Korea Ship and Offshore Research Institute (The Lloyd's Register Foundation \\ Research Centre of Excellence), Pusan National University, Busan 46241, Republic \\ of Korea \\ b Department of Naval Architecture and Ocean Engineering, Pusan National \\ University, Busan 46241, Republic of Korea \\ ${ }^{c}$ Department of Mechanical Engineering, University College London, London WC1E \\ 7JE, UK
}

*Corresponding author. J.K. Paik. E-mail: j.paik@ucl.ac.uk.

\begin{abstract}
Offshore installations are designed to withstand against potential collisions from offshore supply vessels (OSV). Quantitative risk assessment (QRA) provides an overall picture of expected collision frequencies and consequences for the design life of a platform and subsequently estimates the damage repair cost. However, the main challenge of the QRA study is how well various uncertainties are implemented into the model. This study aimed to introduce and demonstrate an advanced and efficient QRA model for the collision between an OSV and a jacket type offshore platform. A set of fifty collision scenarios were selected using probabilistic sampling techniques, and vessel motion analyses were performed to determine collision load characteristics. Extensive nonlinear structural crashworthiness analyses were conducted using advanced computational modelling techniques, and the repair cost of the damaged brace and column members were calculated. Probability exceedance diagrams were established for different consequence parameters, and asset risks were calculated. A comparison study of the design values of damage parameters and repair costs were carried out in association with the NORSOK and HSE risk acceptance criteria. A sensitivity study was carried out to study the effects of various collision load parameters on the structural consequences. The methods and insights developed in this study could be applied to both new and existing offshore platforms and practically useful for the platform owners to aid in their decision-making process towards the risk-based safety analysis of offshore platforms.
\end{abstract}

Keywords: Quantitative risk assessment; Collision; Offshore supply vessel; Offshore jacket platform; Structural crashworthiness; Repair costs 


\section{Introduction}

Offshore installations depend on offshore supply vessels (OSVs) for various supplies such as food, chemical, and equipment. Consequently, they are prone to collision accidents during vessel approach, the transfer operations, or while leaving the platform. Various factors causing an accident include platform or vessel oriented human or equipment errors combined with harsh environmental conditions.

The design principle against the supply vessel includes calculation of both collision frequencies and its associated consequences, which are expected to occur during the operational period of the platform. In other words, the situation calls for a risk-based design approach.

The risk of the offshore installation against potential accidents shall be best estimated using quantitative risk assessment (QRA). Typically, the risk is defined as the product of the frequency of occurrence of a credible collision scenario and its associated consequences [1]. Depending on the type of consequences incurred, three types of risk exist, namely asset, fatality, and environmental risk. Generally, the collision of supply vessel to fixed platforms results in minor consequences, which include significant damage to the substructure of the platform, such as local denting and fracture of legs or braces [see Fig. 1 (a) and (b)], except a case where the total loss of the MHN (Mumbai High Northern) platform [see Fig. 1 (c)]. However, the consequences are primarily governed by the financial cost to repair the damaged parts [2]; therefore, it is crucial to evaluate asset risk and implement suitable measures to mitigate the damage against potential ship impacts.

(a)
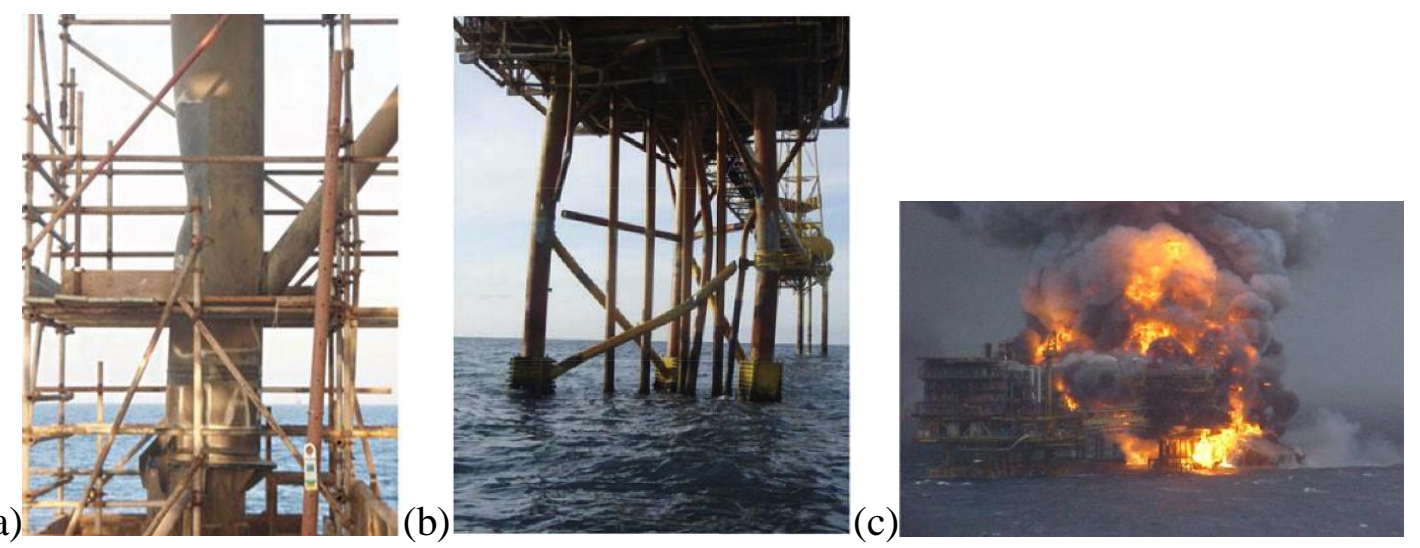

Fig. 1. (a) Supply vessel-ZADCO wellhead platform collision [3], (b) Big Orange XVIII- Ekofisk 2/4-W platform collision [4], (c) Samudra Suraksha- MHN platform collision [5].

The success of a risk assessment methodology depends on how well it incorporates various uncertainties associated with the collision scenarios. For instance, the identification and quantification of all the collision-affecting parameters (such as statistical interpretation of collision accidents and operational conditions), selection of credible collision scenarios, and determination of the load parameters such as ship impact velocity, angle, and location. 
A fundamental challenge in risk assessment is to select credible collision scenarios. These scenarios represent to occur during the design life of the platform. Generally, collision scenarios are selected using either deterministic or probabilistic methods. Often, the former involves the selection of a worst-case collision scenario from past accidents combined with expert judgments. At the same time, the latter employs more sophisticated statistical and probabilistic techniques to arrive at the scenarios. In most cases, the deterministic approach becomes conservative when the platforms are designed based on the selection of the most prominent accident, [such as in the case of the total loss of the MHN (Mumbai High Northern) platform [see Fig. 1(c)], thereby incurring a huge capital loss for the platform owners for ensuring high safety and intact in the event of a collision.

Moreover, the increasing size of the supply vessel, [as observed in regions of Norwegian Continental Shelf (NCS)] and the changing design of supply ship bow and the platform, demands a frequent revision of the industry standards and guidelines [6], which again may prove conservative for other platforms and regions where smaller supply vessels are in operation. Hence a careful selection of the possible and potential collision scenarios should be exercised. Such analysis should be performed separately based on factors such as types of offshore platform and supply vessels, geographical location. In this context, the probabilistic analysis proves to be a more viable option, albeit it involves extensive computational methods.

The fundamental steps and general guidelines on performing QRA for ship-platform collisions have been developed by prominent organizations [2,7-10]. Using AIS (automatic identification system) database, Mujeeb-Ahmed et al. [11] performed passing vessel collision risk to an offshore platform. However, research on the practical application of risk assessment of offshore platform against infield vessel collisions is seldom available.

In this context, the main aim of this study is to develop an advanced and practical risk assessment method for ship collisions to an offshore structure. A demonstration of the developed procedure is carried out with an illustrative example consisting of the collisions between a jacket-type offshore platform and an OSV. A combination of probability and sampling techniques is employed to select fifty credible collision scenarios. Based on the collision loads obtained from the vessel motion analysis, extensive structural crashworthiness analyses using NLFEA (nonlinear finite element analysis) have been performed using advanced computational modelling techniques. The repair cost of damaged tubular members is calculated using a simplified cost model. Combining collision frequency calculated based on historical accident database, various exceedance diagrams are established for structural damage parameters and their repair costs. The design values of the parameters are determined and compared based on the NORSOK (the Norwegian shelf's competitive position) and HSE (Health and Safety Executive) acceptance criteria. Further, A sensitivity analysis of collision load parameters to the structural consequences such as absorbed energy and column and brace deformation have been performed to identify critical collision scenarios. The risk assessment procedure developed in this paper will be 
helpful for the platform owners and analysts in their decision-making process towards the risk-based design of structural requirements and the calculation of asset risk.

\section{Framework for quantitative collision risk assessment}

A systematic and well-defined procedure forms the backbone of a QRA study. Figure 2 shows an overall flow chart of the different steps involved in the collision risk assessment procedure.

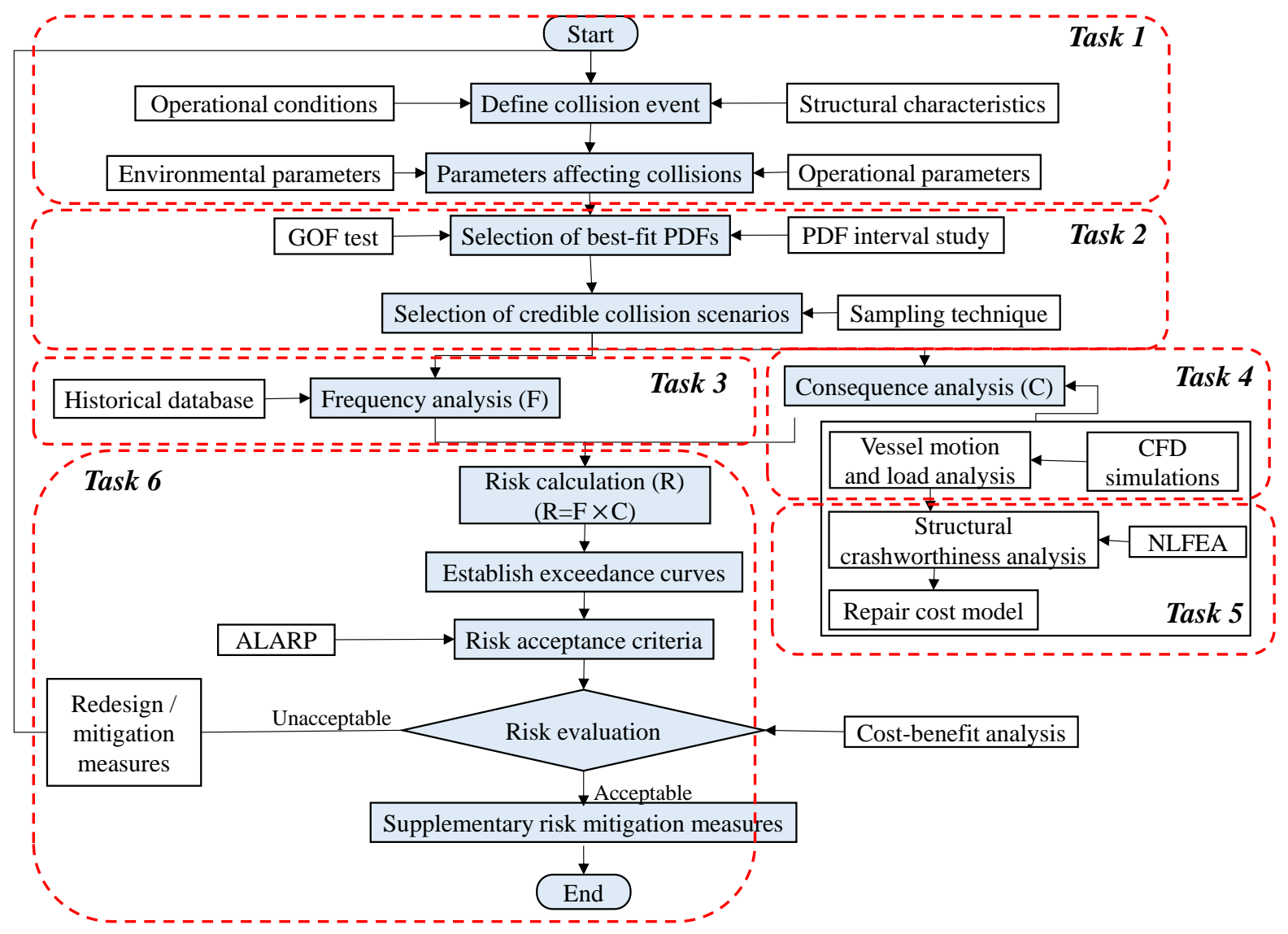

Fig. 2. Procedure for QRA of collisions between a ship and an offshore structure.

Key challenging tasks identified in the procedure include:

- hazard identification

- selection of credible collision scenarios

- calculation of collision frequency

- collision load analysis

- structural crashworthiness analysis

- risk assessment

The current study is the continuation of a series of tasks involved in QRA, where first four tasks have been discussed in [12], and the computational modelling techniques for structural crashworthiness analysis in [13]; however, for continuity, a brief discussion of the same is addressed in the following sections. 


\subsection{Probabilistic selection of collision scenarios}

The risk assessment methodology starts with the definition of a collision event. In this study, the probabilistic sampling approach proposed by Paik [1] is used to select a set of 50 credible collision scenarios between a fixed-type offshore jacket platform and an infield supply vessel. Initially, all types of hazards about the collision event are identified, which includes the collation of data about structural characteristics of the offshore platform and supply vessel in operation; ship voyage history, and its operating condition; and environmental data. Next, the fundamental parameters affecting the collision are identified, for instance, Fig. 3 shows a schematic representation of eleven environmental parameters $\left(\begin{array}{lll}X_{1} & \text { to } X_{8}\end{array}\right)$ involved in a collision, where still water level (SWL) includes the combined action of tide and surge variations. Besides, three-vessel parameters-velocity $\left(X_{9}\right)$, angle $\left(X_{10}\right)$, and location $\left(X_{11}\right)$, are also considered.

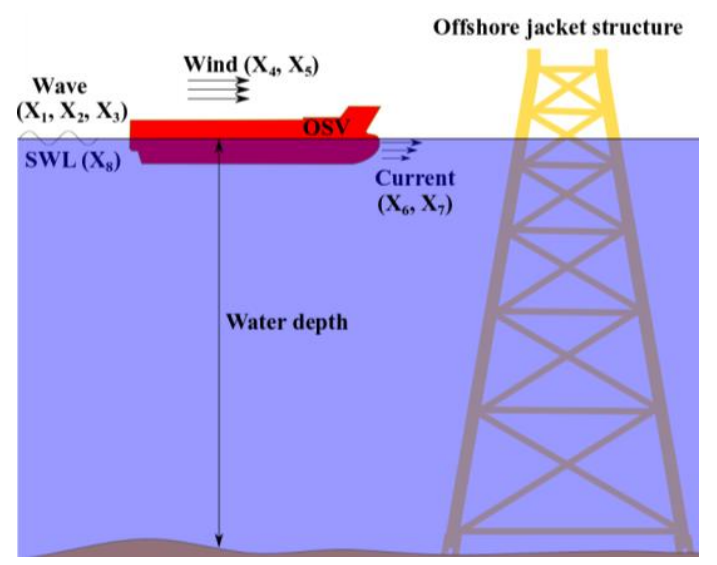

Fig. 3. Schematic representation of different environmental parameters involved in an OSV-platform collision.

In the absence of real metocean data, this study considers a hypothetical oceanic region. Table 1 provides the probabilistic characteristics of each input parameter. The PDFs of environmental parameters were taken from API [14] and DNV GL [15], and assumed distributions were followed for vessel operational parameters.

Table 1. Probabilistic characteristics of environmental and vessel operational parameters.

\begin{tabular}{|c|c|c|c|c|c|}
\hline Symbol & $\begin{array}{l}\text { Random } \\
\text { variable }\end{array}$ & Unit & Distribution & Parameters & Reference \\
\hline$X_{1}$ & $\begin{array}{l}\text { Significant } \\
\text { wave height }\end{array}$ & $\mathrm{m}$ & Weibull & $\alpha=1.81, \quad \beta=1.47$ & $\begin{array}{l}\text { DNV GL } \\
{[15]}\end{array}$ \\
\hline
\end{tabular}




\begin{tabular}{|c|c|c|c|c|c|}
\hline$X_{2}$ & $\begin{array}{l}\text { Zero-crossing } \\
\text { wave period }\end{array}$ & $\mathrm{s}$ & Lognormal & $\mu=0.7+0.95 H_{s}^{0.158}$, & $\begin{array}{l}\text { DNV GL } \\
{[15]}\end{array}$ \\
\hline & & & & $\sigma=0.07+0.1685 e^{\left(-0.0312 H_{s}\right)}$ & \\
\hline$X_{3}$ & $\begin{array}{l}\text { Wave } \\
\text { direction }\end{array}$ & $\mathrm{rad}$ & $\begin{array}{l}\text { Directional } \\
\text { function }\end{array}$ & $s=5$ & $\begin{array}{l}\text { DNV GL } \\
{[15]}\end{array}$ \\
\hline$X_{4}$ & $\begin{array}{l}\text { Wind speed } \\
\text { (1-h avg.) }\end{array}$ & $\mathrm{m} / \mathrm{s}$ & Lognormal & $\alpha=0.61, \quad \beta=0.725$ & API [14] \\
\hline$X_{5}$ & $\begin{array}{l}\text { Wind } \\
\text { direction }\end{array}$ & $\mathrm{rad}$ & $\begin{array}{l}\text { Directional } \\
\text { function }\end{array}$ & $s=5$ & $\begin{array}{l}\text { DNV GL } \\
{[15]}\end{array}$ \\
\hline$X_{6}$ & $\begin{array}{l}\text { Current } \\
\text { velocity } \\
\text { (surface) }\end{array}$ & $\mathrm{m} / \mathrm{s}$ & Lognormal & $\mu=-1.1187, \quad \sigma=3.432$ & API [14] \\
\hline$X_{7}$ & $\begin{array}{l}\text { Current } \\
\text { direction }\end{array}$ & $\mathrm{rad}$ & $\begin{array}{l}\text { Directional } \\
\text { function }\end{array}$ & $s=5$ & $\begin{array}{l}\text { DNV GL } \\
{[15]}\end{array}$ \\
\hline$X_{8}$ & $\begin{array}{l}\text { Still water } \\
\text { level (SWL) }\end{array}$ & $\mathrm{m}$ & Weibull & $\mu=0.984, \quad \sigma=3.245$ & API [14] \\
\hline$X_{9}$ & Vessel speed & $\mathrm{m} / \mathrm{s}$ & Lognormal & $\mu=-0.5102, \quad \sigma=0.5214$ & Assumed \\
\hline$X_{10}$ & $\begin{array}{l}\text { Vessel } \\
\text { position }\end{array}$ & $\mathrm{m}$ & Lognormal & $\mu=1.67, \quad \sigma=0.82$ & Assumed \\
\hline$X_{11}$ & $\begin{array}{l}\text { Vessel } \\
\text { heading }\end{array}$ & $\mathrm{rad}$ & Normal & $\mu=0.5, \quad \sigma=0.785$ & Assumed \\
\hline
\end{tabular}

A probabilistic analysis of the input parameters was carried out to obtain the best-fit PDF, using the goodness-of-fit (GOF) test and PDF interval study, see for more details in Mujeeb-Ahmed and Paik [12]. Finally, a set of 50 collision scenarios was generated using a Latin hypercube (LHS) sampling technique.

\subsection{Collision load analysis}

The collision load analysis includes the external dynamics of time-dependent vessel motions to determine the initial kinetic energy $(E)$ acting on the platform. As shown in Fig. 4, four collision parameters are used to characterize the initial impact load of the ship, namely the collision velocity $(V)$, angle $(\theta)$, horizontal impact location $(r)$, and vertical impact location $(l)$. For selected 50 collision scenarios comprising environment and vessel parameters, the numerical simulations of vessel motions were 
carried out using ANSYS AQWA. Table A.2 lists the results of the load parameters and initial kinetic energies, obtained from [12].

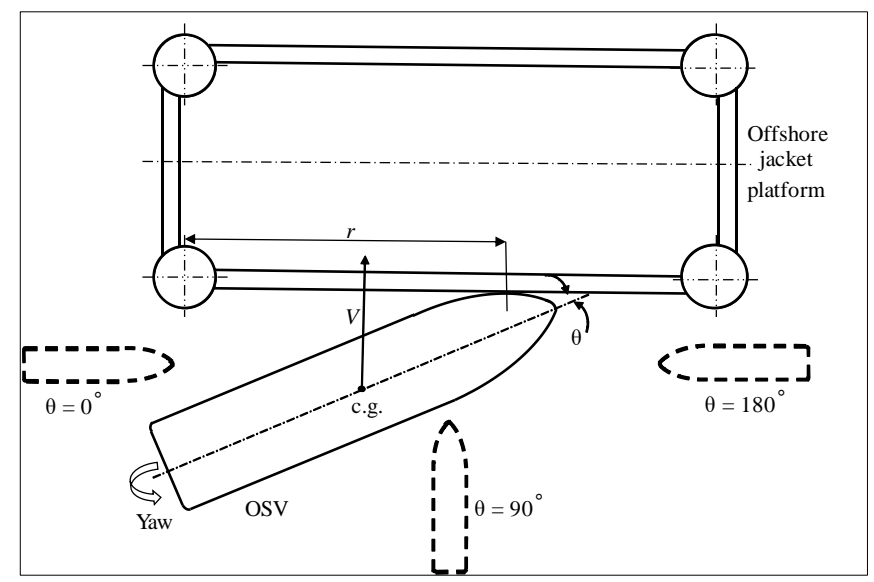

Fig. 4. Simplified 2D model of offshore jacket platform and OSV depicting different load parameters.

\subsection{Structural crashworthiness analysis}

The internal mechanics involves the structural crashworthiness analysis of the platform. The collision load parameters (described in the previous section) are applied to the platform using nonlinear finite element analysis (NLFEA) code, LS-DYNA [16]. Advanced computational modelling techniques are used to capture the nonlinear interaction of collision load and the resulting damage. Figure 5 shows a general flowchart of the procedure for NLFEA, developed by Mujeeb-Ahmed et al.[13]. A brief description of the method is described in the following sections.

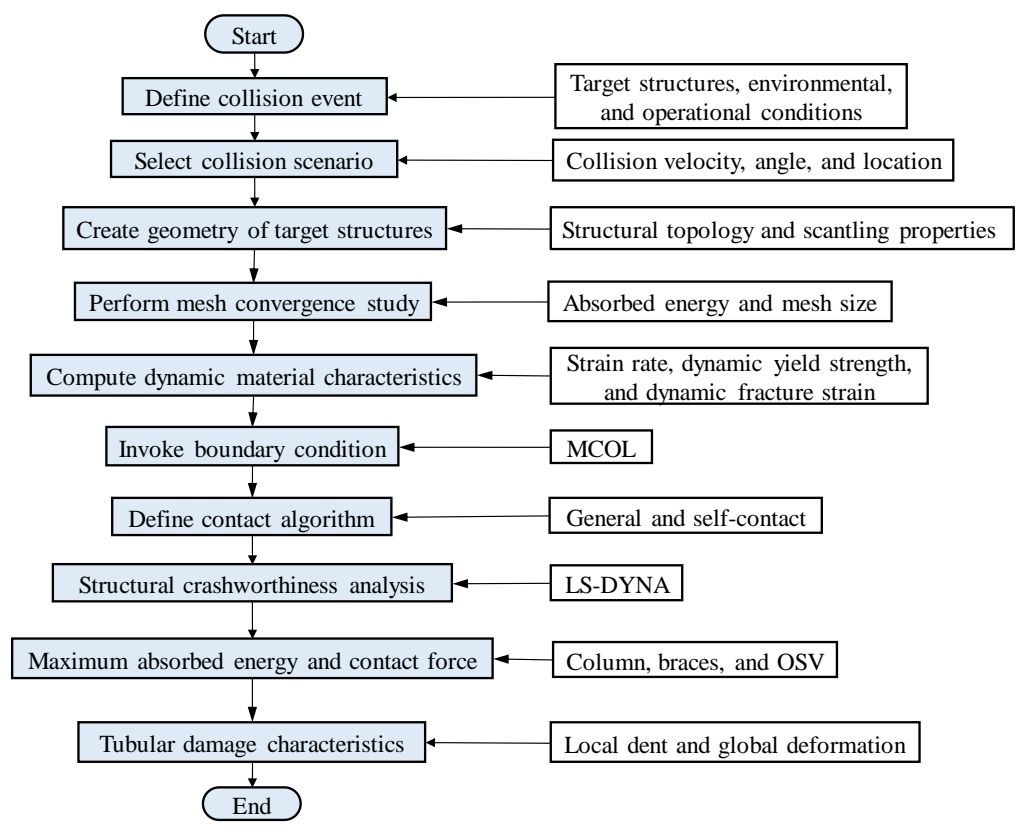

Fig. 5. Procedure for NLFEA of offshore platforms in collision with OSV. 
Based on a shared-energy design principle, the structural deformations of both OSV and jacket are modelled using finite shell elements. Keeping in mind that simulations have to be performed for 50 collision scenarios, a mesh convergence study is performed to determine the optimum mesh size that provides reasonably accurate damage characteristics and capture all failure mechanisms. The dynamic material properties, such as the effect of strain rate on dynamic yield strength $\left(\sigma_{Y d}\right)$ and dynamic fracture strain $\left(\varepsilon_{f d}\right)$ are considered using Cowper-Symonds $(\mathrm{C}-\mathrm{S})$ equation [17]. On feeding C-S coefficients, LS-DYNA automatically accounts $\sigma_{Y d}$; however, $\varepsilon_{f d}$ has to be manually entered, which is calculated using the inverse C-S equation given by Jones [18] as follows:

$$
\varepsilon_{f d}=\xi\left[1+\left(\frac{\dot{\varepsilon}}{C}\right)^{\frac{1}{q}}\right]^{-1} \varepsilon_{f c}
$$

where $C$ and $q$ are coefficients; $\varepsilon_{f c}$ is critical fracture strain and $\xi$ is the ratio of the static and dynamic energies absorbed in a material at rupture. In this study, the energy to failure is assumed to be invariant, i.e., independent of strain rate; then, it may be taken that $\zeta=1[19,20]$.

Further, Hughes and Paik [21] provided an expression to calculate critical fracture strain $\left(\varepsilon_{f_{c}}\right)$ as follows:

$$
\varepsilon_{f c}=\gamma_{1} \gamma_{2} \varepsilon_{f}
$$

where $\varepsilon_{f}$ is the static fracture strain, obtained from the tensile coupon test. Paik et al. [22] provided a test database for various types of steel and aluminium. Accordingly, $\varepsilon_{f}=0.32$ for high-tensile steel is selected for the computations. $\gamma_{1}$ is a factor associated with mesh size $(s)$ and material thickness $(t)$ given by,

$$
\gamma_{1}=d_{1}\left(\frac{t}{s}\right)^{d_{2}}
$$

where $d_{1}$ and $d_{2}$ are coefficients calculated based on the tensile coupon test, and $s$ is the mesh size. Paik and Thayamballi [23] suggested $d_{1}=4.1$ and $d_{2}=0.58$ for 
mild steel having a thickness $(t)$ of $2 \mathrm{~mm} . \gamma_{2}$ is knock-down or correction factor which accounts for local bending due to folding (0.3-0.4); a conservative value of 0.3 is used in this computation.

The strain rate $(\dot{\varepsilon})$ significantly affects the dynamic properties of the material [2426]. However, this could not be directly obtained from LS-DYNA. As a conservative analysis, the maximum strain rate $\left(\dot{\varepsilon}_{m}\right)$, which is observed at the initial contact position between the bow and tubular member, is used where the first fracture usually occurs [27]. The strain at this location is monitored, and the time-derivative of strain would yield the strain rate according to the equation,

$$
(\dot{\varepsilon})_{\mathrm{m}}=(d \varepsilon / d t)_{\text {initial_contact }}
$$

MCOL subroutine of LS-DYNA is utilized to consider the effect of the surrounding water to ship motions during a collision. At each time interval, the program couples structural forces due to ship impact and hydrodynamic forces due to ship motion $[28,29]$.

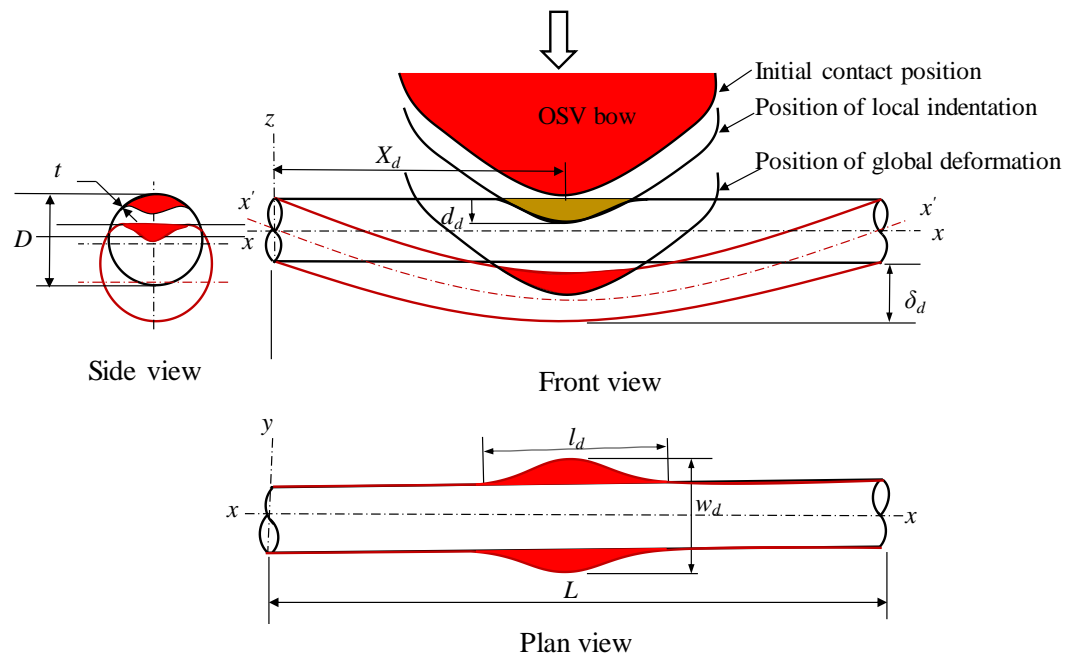

Fig. 6. Definition of local and global damage characteristics of a tubular memberside, front, and plan view.

Both internal contacts in the bow and jacket members and external contacts between the colliding bodies are invoked in the numerical analysis.

The energy absorbed by an offshore jacket dissipates in the form of local denting and global bending of the tubular member as well as the global deformation of the whole platform. The global deformation of fixed-type offshore platforms may be conservatively ignored [30]. Figure 6 shows a schematic representation of the local denting and global deformation characteristics of a brace member subjected to the lateral impact of the OSV bow structure, where $\delta_{d}$ denotes the global deflection; $l_{d}$, 
$w_{d}$, and $d_{d}$ represents the length, width, and depth at the local deformation of the tube, respectively.

\subsection{Repair of tubular members}

In the aftermath of a collision, the damaged members have to be repaired so that it should be able to continue its intended function safely for its designed period of operation. Different repair techniques or practices are available for damaged offshore tubular members [31]. Depending on the extent and severity of the damage, they can be grouped into three major categories - replace/renew, strengthen, or modify. For instance, Fig. 7 (a) shows a replacement part for the underwater repair of the damaged column and braces of a jacket platform [32]. Sveen [33] provided a report of damage assessment and repair of an Oseberg B jacket platform subjected to collision from a submarine. Accordingly, Fig. 7 (b) shows the repair of a damaged diagonal brace member, which includes severe dent and global deflection. It was decided to cut and replace the whole brace rather than reinforce with a grouted sleeve, albeit nonlinear pushover analysis of the platform shows high reserve strength. Figure 7 (c) shows a schematic diagram of the strengthening mechanism using bolts and clamps of a damaged diagonal brace member [34].

(a)
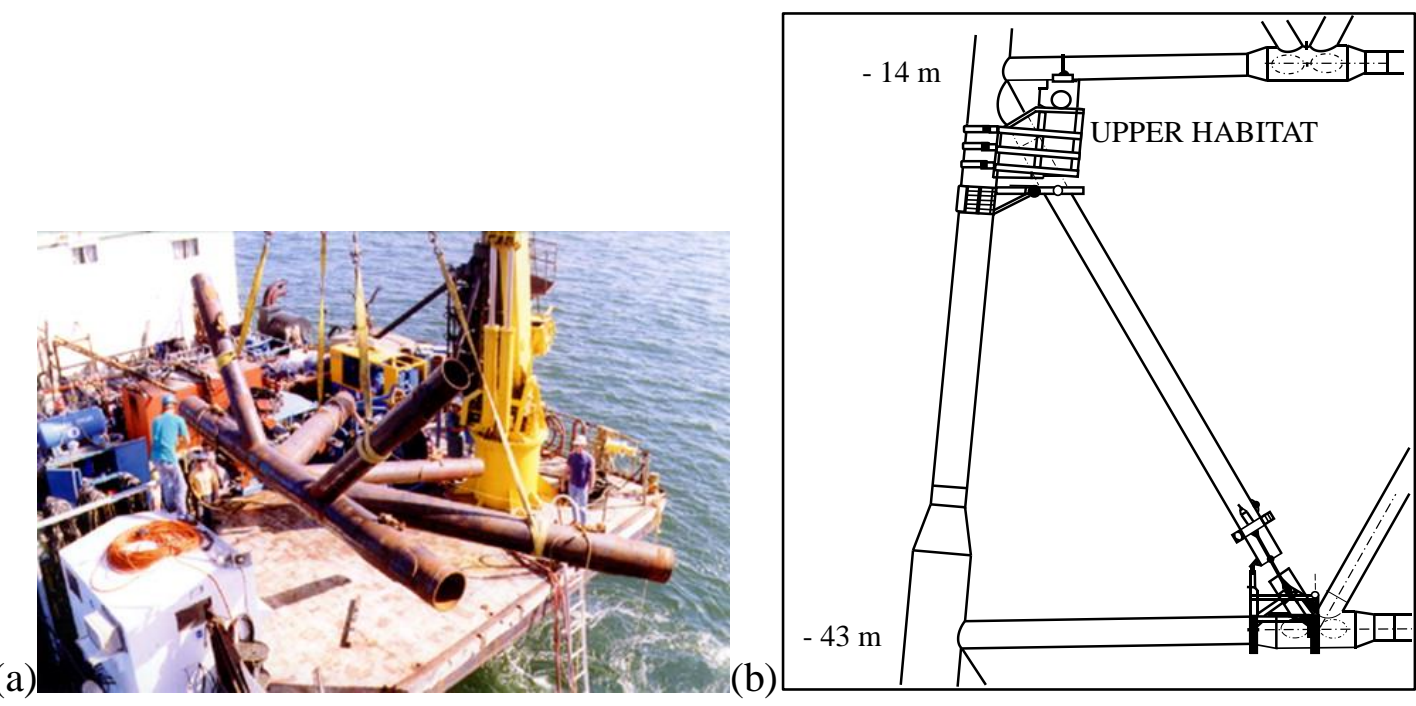


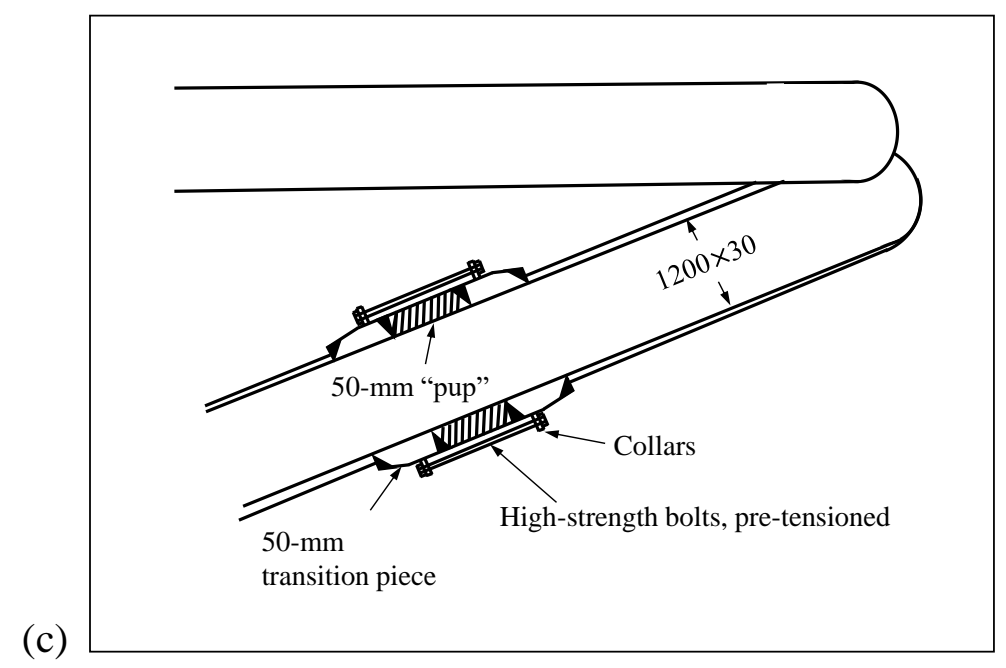

Fig. 7. Typical offshore jacket repair methods: (a) a new replacement part consisting of columns and braces for the underwater repair of jacket platform [32], (b) replace of the damaged brace members of the Oseberg B jacket platform [33], (c) clamping mechanism to strengthen a damaged brace [34].

In general, the decision of the selection of an appropriate repair technique is taken by the platform owner and the design engineers based on the severity of the damage, repair costs, etc. However, in the illustrative example, we assume that the repair action involves only the replacement of the damaged tubular members.

\subsubsection{Repair criteria}

The collision affected by the infield supply vessel consists of mainly minor consequences, such as local denting and fracture of tubular members. In some cases, no repair action may be required because the platform may have sufficient load-carrying capacity to continue its intended function for the design period of its operation. With potential consequences varying from a minor dent to significant deformation, there are no universally accepted industry practices, standards, or recommended criteria that demarcate when to repair or replace the damaged tubular members. In this context, a risk-based repair criterion is proposed based on the exceedance diagrams of the damage characteristics in combination with the risk acceptance criteria. Accordingly, for a given collision scenario, $i$, with normalized maximum global deflection ( $\left.\delta_{d, i, j} / L_{i, j}\right)$ and critical global deflection $\left(\delta_{d, c, j}\right)$,

$$
\text { If } \delta_{d, i, j} / L_{i, j} \geq \delta_{d, c, j}: \text { replace }
$$

Otherwise: neglect

where index $j$ denotes the type of member damaged, e.g., $j=1$ and 2 represent brace and column members, respectively, and index $c$ denotes the critical value of 
deformation. Similarly, for local denting with normalized maximum local dent depth $\left(d_{d, i, j} / D_{j}\right)$ and critical local dent depth $\left(d_{d, c, j}\right)$,

$$
\text { If } d_{d, i, j} / D_{i, j} \geq d_{d, c, j}: \text { replace }
$$

Otherwise: neglect

where $L_{i, j}$ and $D_{i, j}$ represents the length and diameter of the damaged member.

$\delta_{d, c, j}$ and $d_{d, c, j}$ are calculated from their respective exceedance diagrams based on a chosen acceptable criterion.

\subsubsection{Repair cost model}

The calculation of repair costs for offshore structures has been extensively discussed in the literature [35-37]. Typically, the on-site repair operation of the offshore platform is costly compared to land-based structures due to various factors such as operating in dynamic sea conditions (such as underwater welding), the cost of transportation such as equipment, machinery, labours, and engineers. Figure 8 provides some of the main cost components and parameters involved in the repair of offshore structures. This includes the cost of equipment and machinery, raw materials, labours, downtime, and repair techniques. Mathematically, the total repair cost $\left(C_{r}\right)$ can be expressed as,

$$
C_{r}=\sum_{k=1}^{m} \sum_{j=1}^{n} C_{m, k, j}+C_{w, k, j}+C_{d, k, j}+C_{e m, k, j}+C_{t, k, j}
$$

where

$k=$ number of members damaged,

$j$ = type of member damaged (column/brace),

$C_{m}=$ cost of material (includes grade and amount of steel used),

$C_{w}=$ cost of welding (includes weld material, labour unit cost, man-hour),

$C_{d}=$ cost of downtime,

$C_{e m}=$ cost of hiring equipment and machinery (such as welding, grouting, bolting, and clamping operations),

$C_{t}=$ cost of transportation (such as engineers, labours, equipment, and machinery). 


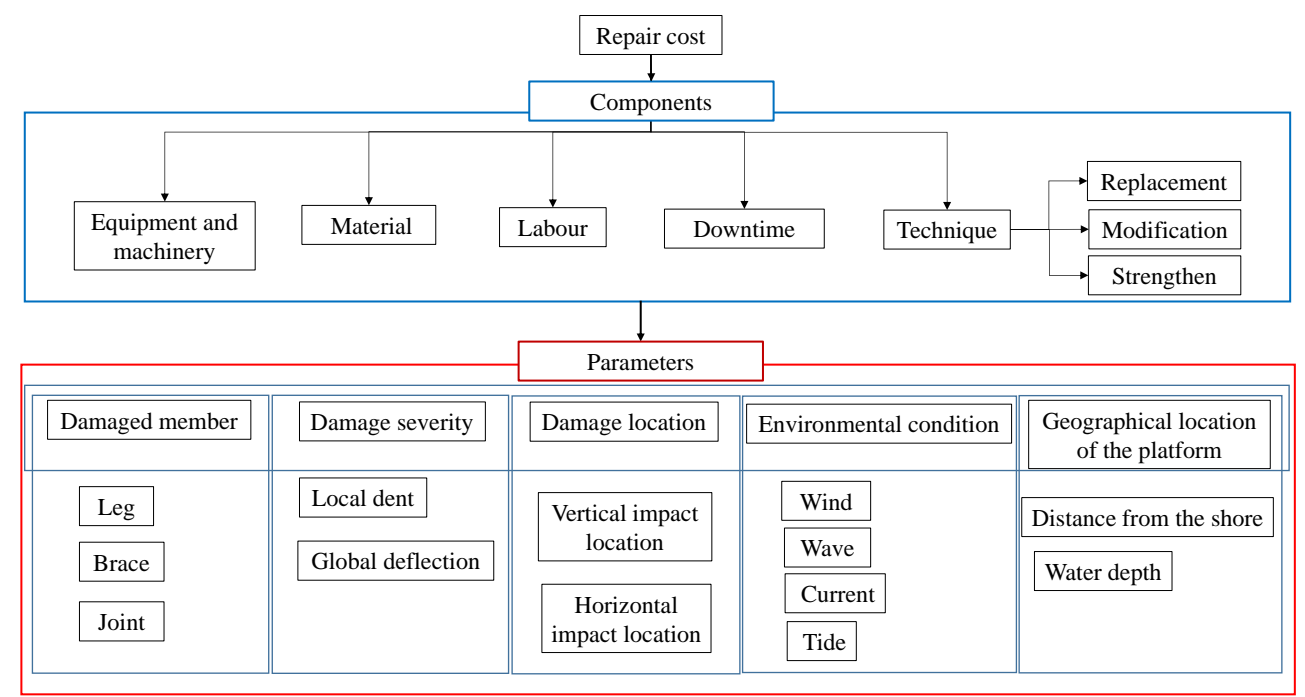

Fig. 8. Different components and parameters involved in the estimation of the repair cost.

Each cost component is, in turn, determined by the collision parameters such as damage characteristics (severity, location, and type of member damaged), environmental condition, and the geographical location of the platform [see Fig. 8]. For instance, if the vertical damage location is below the mean sea level (MSL), expensive underwater welding may be required. Paik et al. [38] provided an analytical expression for calculation of the repair cost of a ship in terms of the damaged steel volume $\left(V_{d}\right)$ and steel cost $\left(C_{s}\right)$ as:

$$
C_{r}=7.85 \times V_{d} \times C_{s} \times \lambda \quad(\text { in USD })
$$

where $\lambda$ is the additional cost accounting for factors such as cutting, building, and fitting of the damaged area and damaged volume, $V_{d}$ for the tubular member is calculated using the expression,

$$
V_{d}=\pi L_{m} t_{m}\left(D_{m}-t_{m}\right)
$$

where $L_{m}, D_{m}$ and $t_{m}$ denotes length, diameter, and thickness of the tube at the damaged section. Paik et al. [38] assumed the total repair cost of a ship is twice $(\lambda=2)$ as much as in the fabrication of a new-building process (where $C_{s}=8000$ USD/ton). On the other hand, the repair of a jacket platform is typically an on-site operation, which is expensive as compared to yard-based ship repairs (Eq.7 gives an estimate of various additional cost components). Therefore, in the illustrative example, we assumed that the repair cost of the offshore jacket platform is five times as in the process of the fabrication of a new platform $(\lambda=5)$, where the fabrication cost of 
steel of a new platform is 20,000 USD/ton [39]. In reality, the cost of steel ( $\left.C_{s}\right)$ varies with time, based on various factors such as availability, market demand, and the country of its production.

\subsection{Calculation of collision frequency}

Among the different approaches of calculating collision frequency, includes historical accident data, fault tree, event tree, and human reliability analysis. In this study, the historical accident database is used, which provides realistic estimates of frequencies from previous accident experience. Following the study conducted by Mujeeb-Ahmed and Paik [12], the average collision frequency is found to be $8.3 \times 10^{-4}$ per platform-year based on the statistical information from the worldwide offshore accident database (WOAD) - a prime source of offshore accident database [40]. The same value is assigned equally for all collision scenarios. Figure 9 shows the number of collision accidents that occurred from the passing and visiting vessels during 19702014. The current QRA study is the continuation of tasks initiated by Mujeeb-Ahmed and Paik [12]; therefore, in the illustrative example, collision accidents until 2014 were considered; however one may add more recent data to calculate updated collision frequency.

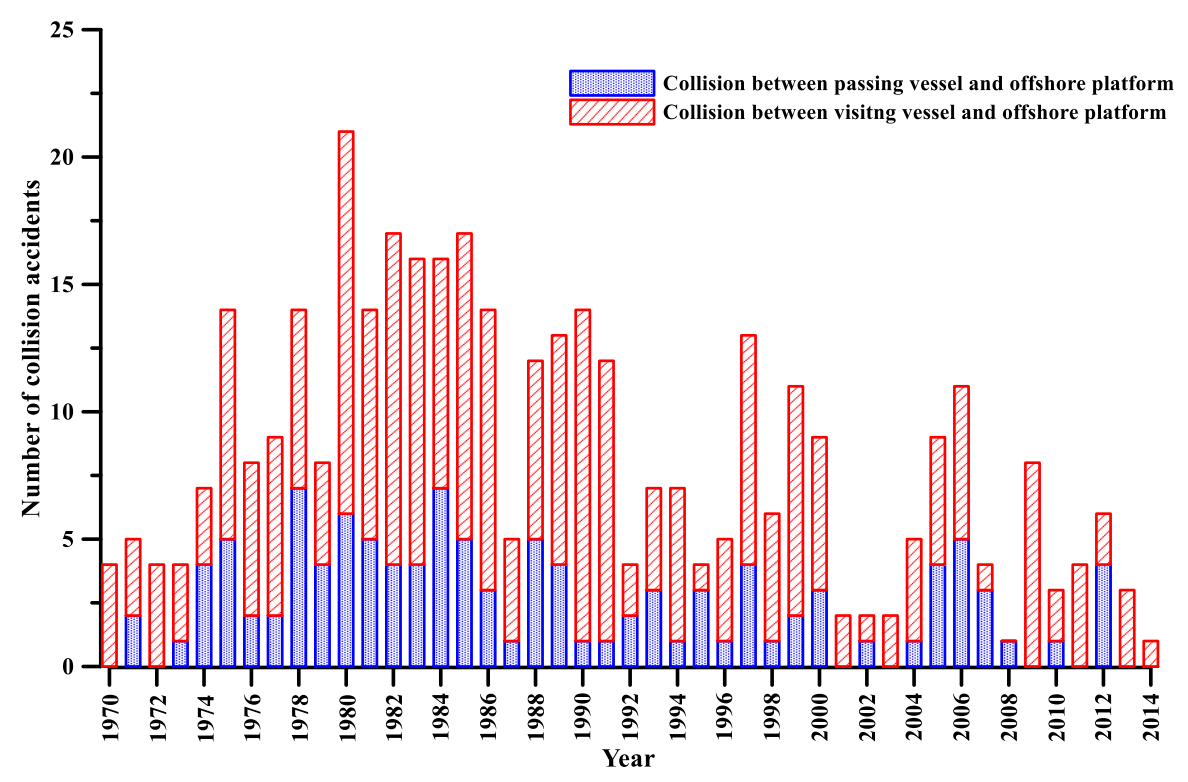

Fig. 9. The annual distribution of the worldwide collision accidents between offshore installations and visiting/passing vessels collated during 1970-2014.

\subsection{Establishment of exceedance diagrams and risk acceptance criteria}

The exceedance diagrams are generated for damage characteristics and repair costs using calculated collision frequencies [1]. As discussed in section 2.4.1, to decide the design parameters based on exceedance diagrams, it is essential to define an acceptable risk criterion [41,42]. NORSOK [7] stipulates some basis and guidelines for the selection of risk acceptance criteria. Alternatively, one may follow the ALARP 
(as low as reasonably practicable) principle to study cost-benefit analysis in arriving risk acceptance criteria.

Different classification societies and regulatory committees offered acceptance criteria and design guidelines regarding damaged platforms under vessel collision. For instance, DNV GL [43], HSE [40], and API [30] require that a platform damaged under accidental loads should survive one-year environmental storm loads in addition to functional loads. NORSOK [6] and Moan [44] provided a stricter criterion with an annual exceedance probability criteria of $10^{-2}$. HSE [45] specifically recommends that the impact energy absorbed by a fixed steel jacket structure should be taken at least $4 \mathrm{MJ}$ unless collision hazards and consequences study specific to an installation shows that a lower value is appropriate. This guideline is particularly applicable for jacket single components (such as horizontal, diagonal braces, and columns) assessed in vessel collision. ABS [2] specifies that all the acceptance criteria and corresponding risk shall be defined and documented by the platform owner.

Further, such criteria should define the energy absorption design requirements for individual structural elements (such as a horizontal brace) for both local denting and global bending mechanisms. Besides, they should also follow the Canada Oil and Gas Installations Regulations [46], which states that every offshore platform shall be capable of absorbing the impact energy of at least 4 MJ from a vessel without endangering any person or the environment. In reality, there are no generally accepted risk criteria, and specific platform owners or the design engineers take the final call. In the illustrative example, both HSE and NORSOK criteria are considered to compare their impact on the design risk values of structural damage requirements and total repair cost.

\section{Illustrative example}

\subsection{Target structures}

A demonstration of the applicability of the procedure has been carried out using an illustrative example comprising of collisions between a four-legged offshore jacket platform installed at a water depth of $120 \mathrm{~m}$ and a modern 8546-ton OSV, see Fig. 10. Table 2 gives the main characteristics of the target structures.

Table 2. Principal characteristics of target structures.

\begin{tabular}{llll}
\hline $\begin{array}{l}\text { Offshore jacket } \\
\text { platform }\end{array}$ & Details & OSV & Details \\
\hline Total height & $148 \mathrm{~m}$ & Overall length, $L_{O A}$ & $99.71 \mathrm{~m}$ \\
Freeboard & $20 \mathrm{~m}$ & Design beam, $B$ & $23.25 \mathrm{~m}$ \\
$\begin{array}{l}\text { Brace diameter, } \\
D_{1}\end{array}$ & $1 \mathrm{~m}$ & Design draft, $\Delta$ & $7.1 \mathrm{~m}$ \\
Brace wall & $0.03 \mathrm{~m}$ & Displacement & 8546 tons \\
\hline
\end{tabular}


thickness, $t_{1}$

Leg diameter, $D_{2} \quad 2 \mathrm{~m} \quad$ Longitudinal radius of gyration, $K_{x x} \quad 8.16 \mathrm{~m}$

$\begin{array}{lll}\text { Leg batter } & 1: 7 \quad \text { Transverse radius of gyration, } K_{y y} & 25 \mathrm{~m}\end{array}$

Leg wall thickness, $\quad 0.06 \mathrm{~m} \quad$ Vertical radius of gyration, $K_{z z} \quad 26 \mathrm{~m}$ $t_{2}$

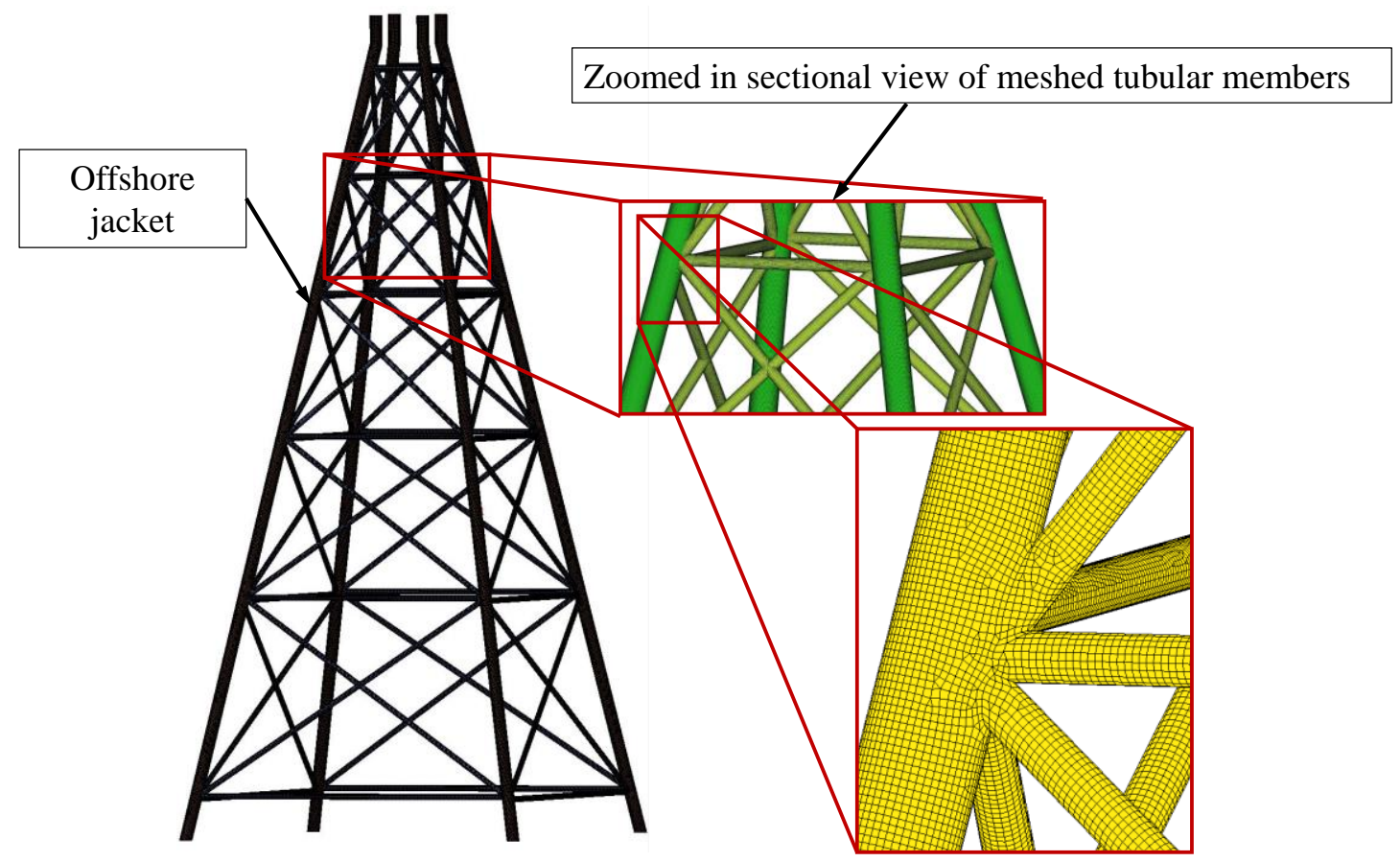

Fig. 10. A substructure segment of four-legged offshore jacket substructure (left); magnified sectional view of the meshed tubular members (right).

The jacket substructure consists of both horizontal and X-configured diagonal braces. For simplicity, the complexities at tube joints arising from increased thickness due to joint cans and brace stubs, welding effects, and residual stresses are not considered in the study. To distinguish the different damaged members involved in a collision scenario, tubular members are categorized into columns and braces (horizontal, right-sided, and left-sided). Figure 11 shows the ID and characteristic dimension of each member. 


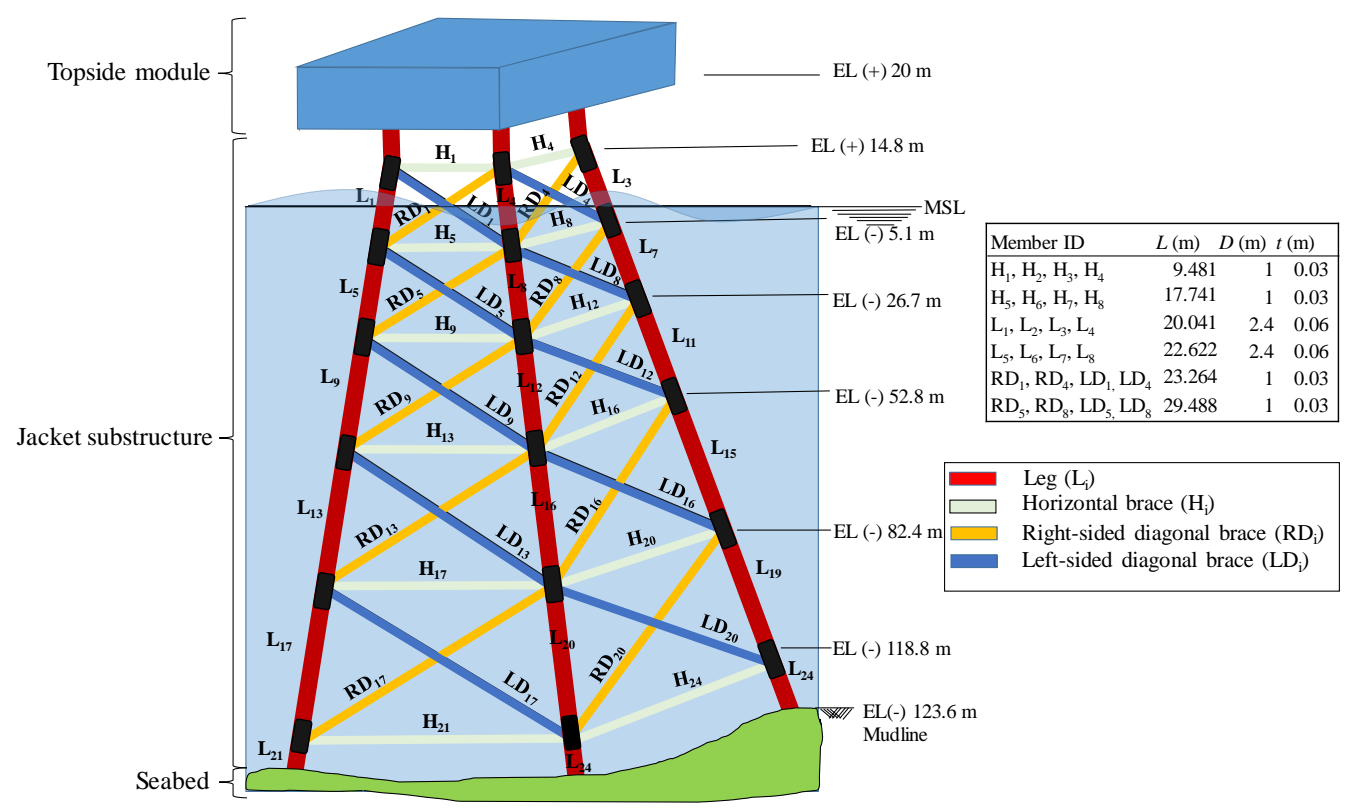

Fig. 11. Schematic representation of a jacket platform showing the elevation and ID of different members.

API [47] guidelines are followed to check compactness criteria against excessive local denting and bending of the tubular members. Accordingly, allowing for a limited plastic rotation capacity of the braces, the thickness of the column and brace parts are selected in compliance with the condition $9000 / \sigma_{Y}<D / t<15200 / \sigma_{Y}$, where $\sigma_{Y}$ is yield strength (in MPa).

The bow forecastle protrudes outwardly more than the bulb; therefore, for identifying damage location with ease, the bow is divided into the forecastle and bulb, as shown in Fig. 12.

(a)

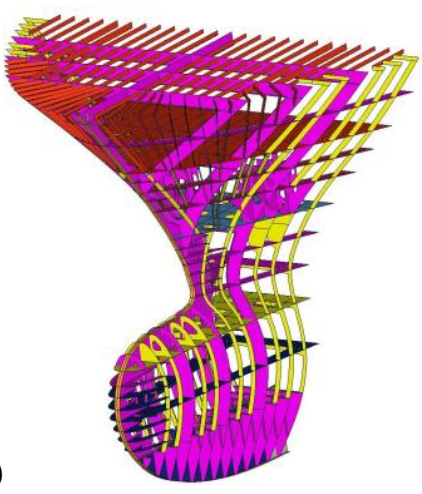

(b)

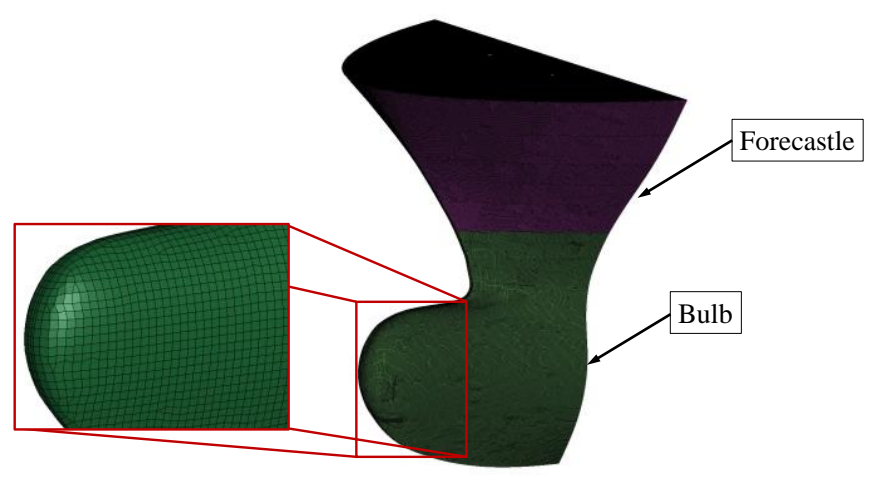

Fig. 12. The bulbous bow model used in the study: (a) internal components and configuration; (b) meshed model showing the forecastle and bulb at the top and bottom, respectively. 


\subsection{Extent of target structures}

A complete substructure part of the jacket is modelled to consider the force and energy distribution among the columns and braces during a collision. The dynamics of the topside module and the leg foundation are ignored. The platform topside has enough freeboard to avoid any possible collision from the vessel.

A bulbous bow model provided by DNV GL [48] is used in the study (see Fig. 12). Table A.1 provides further details on internal configurations and scantling features. Figure 13 describes a collision setup where a series of yellow lines shows the distribution of the total mass of the vessel at the centre of mass to the bow structure. The total weight of the ship (full-load condition) is applied to the bow structure using a 'constrained_node_rigid_body' card in LS-DYNA. For the OSV considered in this study, the centre of the mass is located at a longitudinal distance of $41.5 \mathrm{~m}$ from the vessel aft, which is calculated based on the vessel hydrostatics and represents the total weight of the OSV in a full-load condition approaching a platform, where much of the weight (e.g., supplies) is located near the aft side of the vessel.

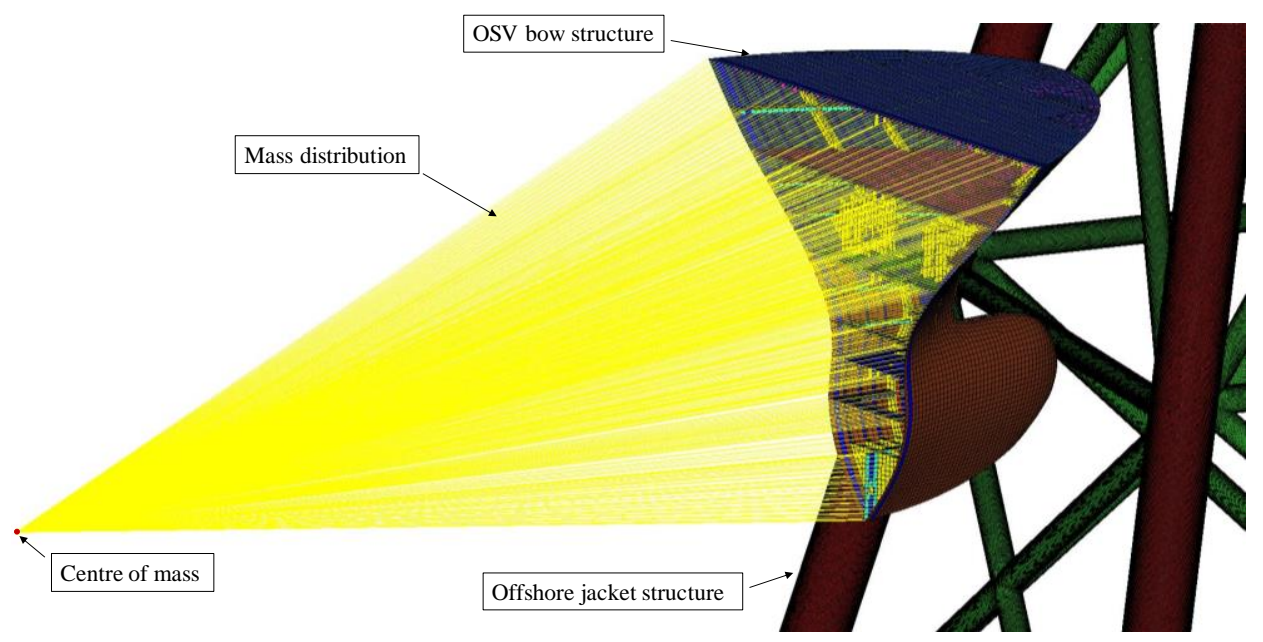

Fig. 13. An example of a collision scenario demonstrating the numerical setup for crashworthiness analysis, a group of straight lines shows the distribution of the total mass of the OSV from its centre of mass to the bow structure.

\subsection{Mesh modelling}

The deformation in target structures is modeled by using four-node Belytschko-Lin-Tsay plate-shell elements [49] based on Reissner-Mindlin kinematic assumption with five through-the-thickness integration points. Reissner-Mindlin theory is the most versatile than other approaches and explicitly considers shear deformations accounting mid-surface displacements and rotary inertia [50]. Also, it is robust to large strain with nonlinear behaviour and prevents zero-energy modes with an advantage of time efficiency [51]. A commonly used shear factor of 0.833 for scaling transverse shear is used in the study.

Before simulating 50 collision scenarios involving expensive computational efforts, a mesh convergence study will provide optimum mesh size. For simplicity, the mesh convergence study is performed for a collision scenario having maximum collision 
velocity identified among all the collision scenarios (i.e., scenario-11 in Table A.2), where the bow impacts a horizontal brace member with a velocity of $1.65 \mathrm{~m} / \mathrm{s}$. To consider different structural interactions among jacket tubular members as well as various internal structural components in the bow structure, both the jacket and bow structures have meshed with the same size. Also, rectangular plate-shell elements were mostly used to mesh the target structures, which is computationally efficient than the triangular elements [52].

As discussed before in Eq.1 that the dynamic fracture strain of the material depends on the chosen mesh size. Therefore, the absorbed energy, which accounts for nonlinear stress and strain, is chosen as the criteria for proving mesh refinement. Accordingly, Fig. 14 (a) demonstrates the results of absorbed energy for seven different element sizes - 600, 400, 250, 200, 150, 100, and $50 \mathrm{~mm}$.

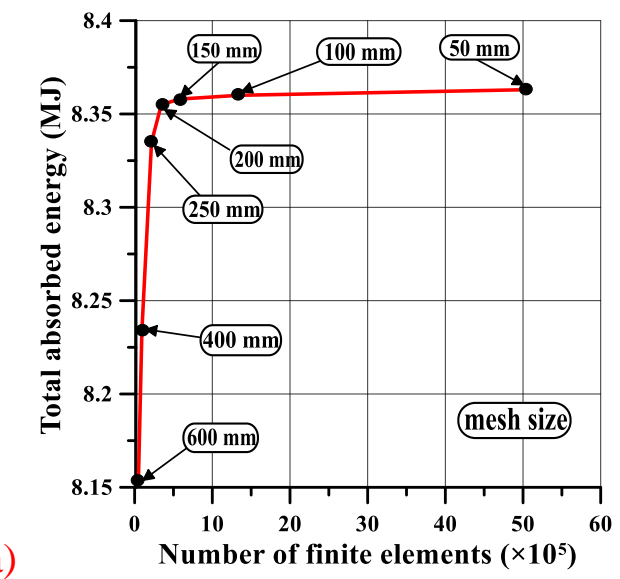

(b)

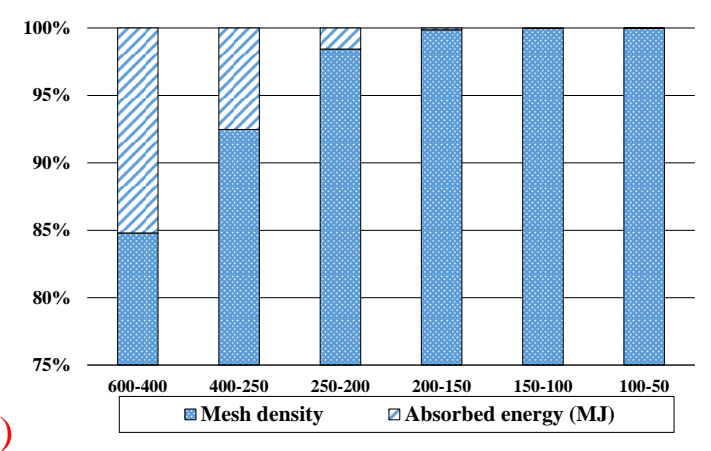

Fig. 14. Results of mesh convergence study: (a) total energy absorbed (both platform and the vessel) and the number of finite elements corresponding to various mesh sizes, (b) percentage increase in absorbed energy with an increase in mesh densities.

Figure 14 (b) shows that with an increase of mesh size after $200 \mathrm{~mm}$, there is no considerable refinement in the absorbed energy (only $0.0007 \mathrm{MJ}$ ), while the number of elements corresponding to $50 \mathrm{~mm}$ is approximately five times larger as compared to $200 \mathrm{~mm}$. Therefore, refinement past $200 \mathrm{~mm}$ mesh size is an inefficient application of FEA and is chosen to be the 'best size' for modelling jacket and OSV for all collision scenarios. Further, the mesh size is within the criteria of 5-10 times thickness as suggested by Storheim an Amdahl [53]. Fig. 10 and 12 (b) show the mesh details in the jacket and OSV bow, respectively.

\subsection{Material modelling}

Accurate input of material properties is essential for performing structural analysis, especially that involves nonlinear failure mechanisms associated with collision scenarios. Table 3 provides the type of steel and its mechanical properties used for the target structures, which are made of high-tensile steel DH36 material with a yield stress of $383.7 \mathrm{MPa}$. 
In addition to this, a true stress-strain curve of the material obtained from the MPDAS (Mechanical Property Database Management) software, developed by Paik et al. [22], is used to capture the fracture accurately (see Fig. 15). As discussed in section 2.3, the scenario having maximum collision velocity (i.e., scenario-11) is identified, and the strain rate is calculated based on the derivative of the plastic strain measured at the initial contact location of bow and platform. The dynamic fracture strain is calculated using the inverse C-S equation. Accordingly, the dynamic fracture strain values are calculated separately for the ship bow, brace, and column members (see Table 4), which is therefore used in the simulation of all collision scenarios.

Table 3 Mechanical properties of target structures [52].

\begin{tabular}{|c|c|}
\hline Properties (unit) & Description \\
\hline Type of steel & $\begin{array}{l}\text { High-tensile steel, } \\
\text { DH36 }\end{array}$ \\
\hline Density, $\rho\left(\mathrm{kg} / \mathrm{m}^{3}\right)$ & 7850 \\
\hline Modulus of elasticity, $E$ (GPa) & 205.8 \\
\hline Poisson's ratio, $v$ & 0.3 \\
\hline Yield stress, $\sigma_{Y} \quad(\mathrm{MPa})$ & 380 \\
\hline $\begin{array}{ll}\text { Cowper-Symonds } & C \quad\left(s^{-1}\right) \\
\text { coefficients } & q\end{array}$ & $\begin{array}{l}3200 \\
5\end{array}$ \\
\hline
\end{tabular}

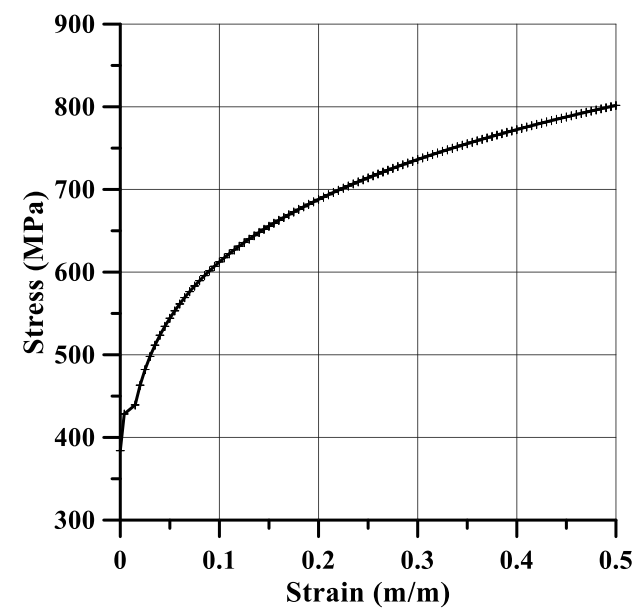

Fig. 15. True stress-strain curve of DH36 high-tensile steel.

Table 4. Computed dynamic fracture strain used for numerical analysis.

\begin{tabular}{llllll}
\hline Structure & $\begin{array}{l}\text { Strain rate, } \\
\dot{\varepsilon}(/ \mathrm{s})\end{array}$ & $\begin{array}{l}\text { Finite } \\
\text { element }\end{array}$ & $\begin{array}{l}\text { Plate/tube } \\
\text { thickness, }\end{array}$ & $\begin{array}{l}\text { Critical } \\
\text { fracture }\end{array}$ & $\begin{array}{l}\text { Dynamic } \\
\text { fracture }\end{array}$ \\
\hline
\end{tabular}




\begin{tabular}{|c|c|c|c|c|c|}
\hline & & $\begin{array}{l}\text { size, } s \\
(\mathrm{~mm})\end{array}$ & $t(\mathrm{~mm})$ & strain, $\varepsilon_{f c}$ & strain, $\varepsilon_{f d}$ \\
\hline Bow & & 200 & 12 & 0.0769 & 0.0609 \\
\hline Column & 3.95 & 200 & 60 & 0.1958 & 0.1551 \\
\hline Brace & & 200 & 30 & 0.1309 & 0.1037 \\
\hline
\end{tabular}

\subsection{Boundary modelling}

The effect of soil-structure interaction at the damaged area is negligible, especially for minor collisions. Therefore, the platform legs are assumed to be fixed at the bottom. To accurately capture the motion and stability of the vessel during a collision, the MCOL subroutine of LS-DYNA is used to couple the hydrodynamics loads of the vessel with structural contact loads [54-57]. In the analysis, the added mass coefficients for surge, sway, and yaw motions of ships are taken as $0.05,0.85$, and 0.21 , respectively [58].

\subsection{Contact modelling}

'Automatic_surface_to_surface' and 'automatic_single_surface' cards of LS-DYNA are used to model external contact between ship and platform and internal contacts among different parts of the ship, respectively [59]. Modelling frictional energy in ship-offshore platform collisions is challenging, as it depends on various factors such as surface characteristics (e.g., grain feature), external conditions (e.g., temperature, moisture, and lubrication), and collision scenarios [60]. The change in collision angle and the contact area between different components of bow structures and the impacted tubular within the course of a collision significantly affects the energy dissipated by friction. For instance, to accurately measure collision absorbed energy, Liu et al. [61] found that a higher frictional coefficient of 0.45 should be defined for a sliding (or glancing) collision as compared to 0.3 used for a head-on ship collision scenario.

In industry practices for numerical simulations involving ship collisions, the frictional coefficient in the range of $0.1-0.3$ is often adopted to simplify the problems associated with friction [1]. In this study, we assume a constant frictional coefficient of 0.3 , which is commonly used in ship collisions, e.g., see [56,59,62,63], and the static and dynamic frictions are the same [64].

\section{Results and discussions}

Following the procedure described in section 2, NLFEA was carried out for 50 collision load scenarios (provided in Table A.2). Figure 16 shows an example of a collision scenario-27, depicting the enlarged view of measuring global deformation and local denting characteristics of a damaged horizontal brace member. The local dent characteristics - dent depth, breadth, and length, are monitored based on the nodal displacements of the elements. The global deformation is measured with respect to the deflection of the neutral axis of the damaged member from its initial position. 


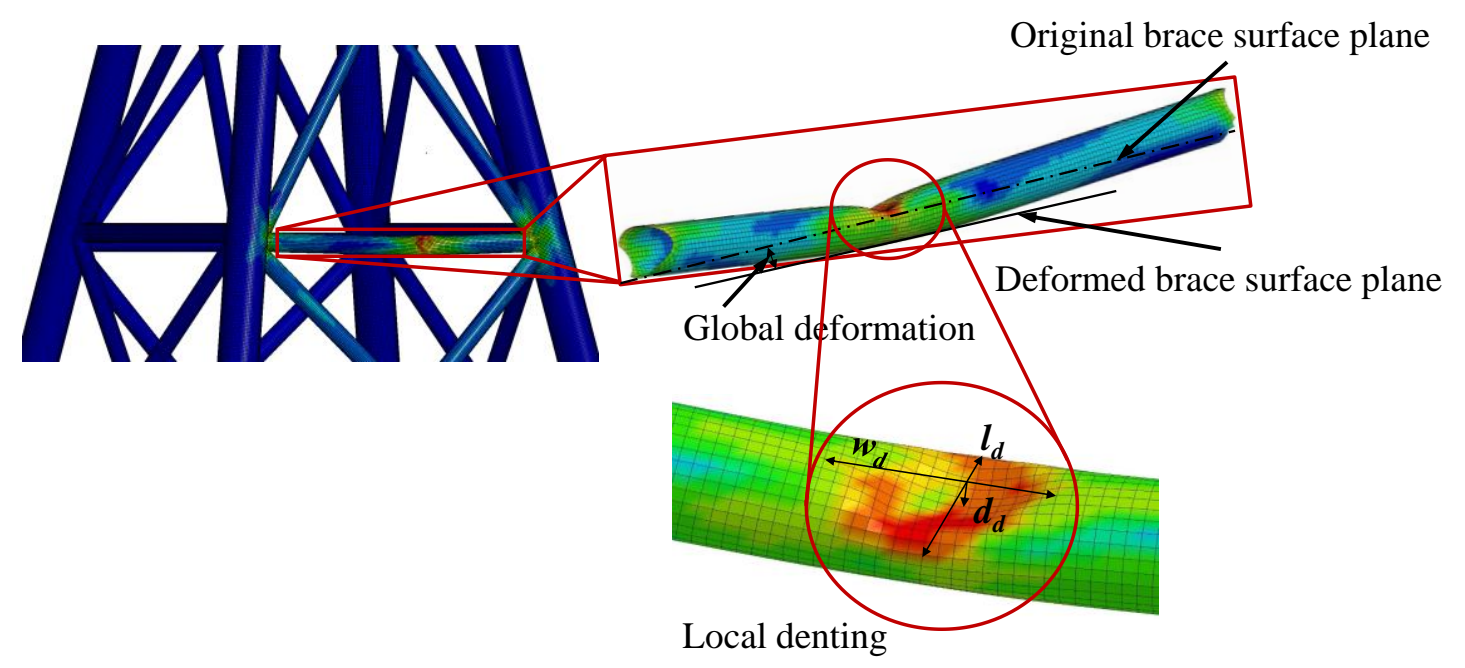

Fig. 16. An example of a collision scenario (scenario-27) showing global deformation and local dent characteristics of a damaged horizontal member $\left(\mathrm{H}_{8}\right)$.

\subsection{Damage characteristics}

Based on the type of structural consequences, the scenarios can be classified into major and minor collisions. As such, Fig. 17 shows examples of the damage patterns of major collision scenarios (11 and 47), demanding immediate repair measures, while scenarios 15 and 18 (see Fig. 18) consists of mainly minor dents, where repair actions may be safely disregarded. Few scenarios show the presence of fracture in the tubular member, for example, scenarios 19 and 33, as shown in Fig. 19. The occurrence of the fracture, especially in horizontal and diagonal brace members, can be attributed to the low dynamic fracture strain value associated with the brace members.

(a)

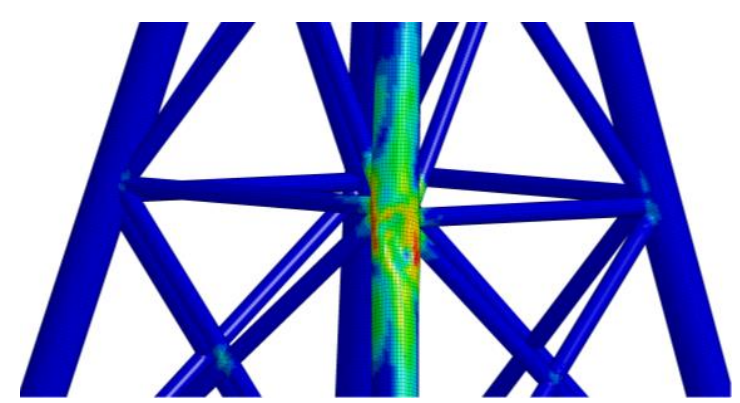

(b)

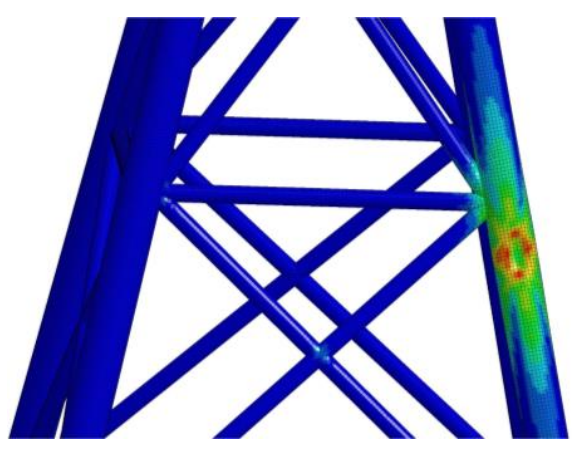

Fig. 17. Examples of major collision: (a) scenario-11 [column $\left(\mathrm{L}_{5}\right)$ ], (b) scenario - 47 [column $\left(\mathrm{L}_{8}\right)$ ]. 
(a)

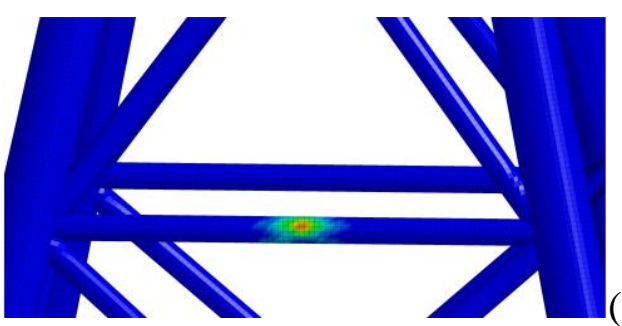

b)

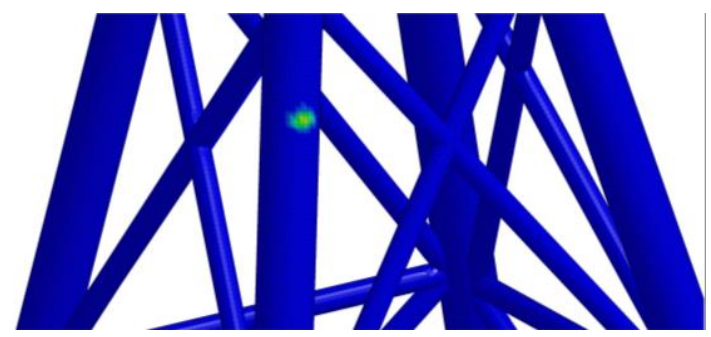

Fig. 18. Examples of minor dent: (a) scenario-15 [horizontal brace $\left(\mathrm{H}_{5}\right)$ ], (b) scenario - 18 [column $\left.\left(\mathrm{L}_{1}\right)\right]$.

(a)
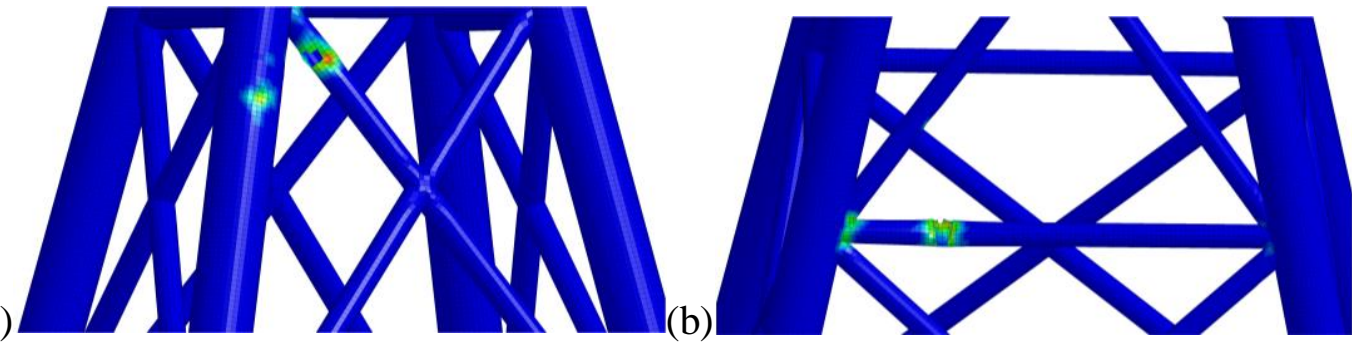

Fig. 19. Examples of scenarios showing occurrences of fracture: (a) scenario - 19 [diagonal brace $\left(\mathrm{LD}_{1}\right)$ ], (b) scenario-33 [horizontal brace $\left(\mathrm{H}_{5}\right)$ ].

Due to closely interconnected tubular members and relatively large size of the bow, the bow may contact with multiple tubular members where the distribution of load occurs. For instance, Fig. 20 shows scenarios 37 and 50, where the impact occurs in columns and braces. The ship impacts at multiple members either simultaneously or a member followed by another member after changing its course.

(a)

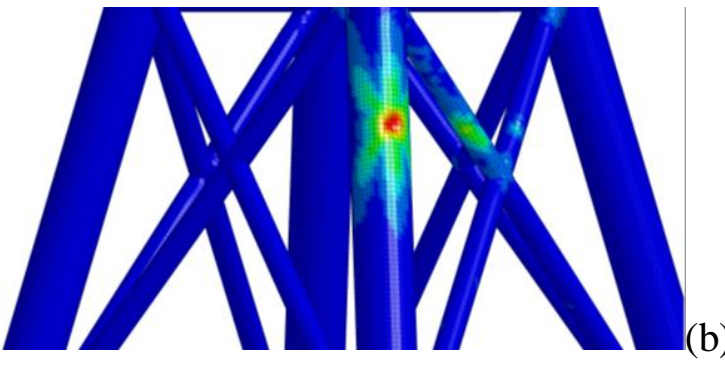

(b)

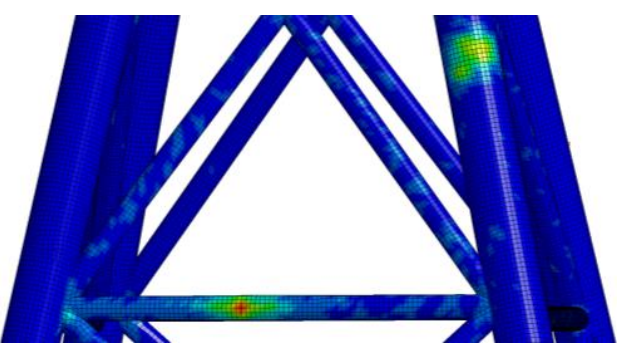

Fig. 20. Examples of collision scenarios showing multiple impacts: (a) scenario-37 [column $\left(\mathrm{L}_{4}\right)$ and diagonal brace $\left(\mathrm{LD}_{4}\right)$ ]; (b) scenario-50 [column $\left(\mathrm{L}_{4}\right)$ and horizontal brace $\left.\left(\mathrm{H}_{5}\right)\right]$.

\subsection{Absorbed energy and collision force}

To validate the results obtained in this study, Fig. 21 (a) shows the comparison of the force-deformation plots of scenario-11 with the various empirical models obtained from DNV GL [65], Cho et al. [66], Furnes and Amdahl [67], Ellinas and Walker [68], which is derived from experimental studies and the theoretical model of Wierzbicki and Suh [69]. It can be seen that the results of the present study match closely with 
others, especially at low impact velocities. However, the curves tend to diverge with increasing velocity; this may be due to the effect of nonlinearities arising from geometric, material, and contact properties at higher impact velocities.

To capture realistic collision scenarios, we performed the analyses by considering the deformations of both ship and jacket structures. For example, Fig. 21 (b) shows the force-deformation curves for collision scenario-11, obtained separately for the column, brace, and OSV bow structures. As expected, the bow absorbed the lowest energy with maximum absorbed energy found to be $0.25 \mathrm{MJ}$, which is only $1.21 \%$ of the total impact energy. Though this amount is insignificant as compared to total energy involved, however, the deformation of the bow is taken into account, considering better accuracy of the results.

(a)
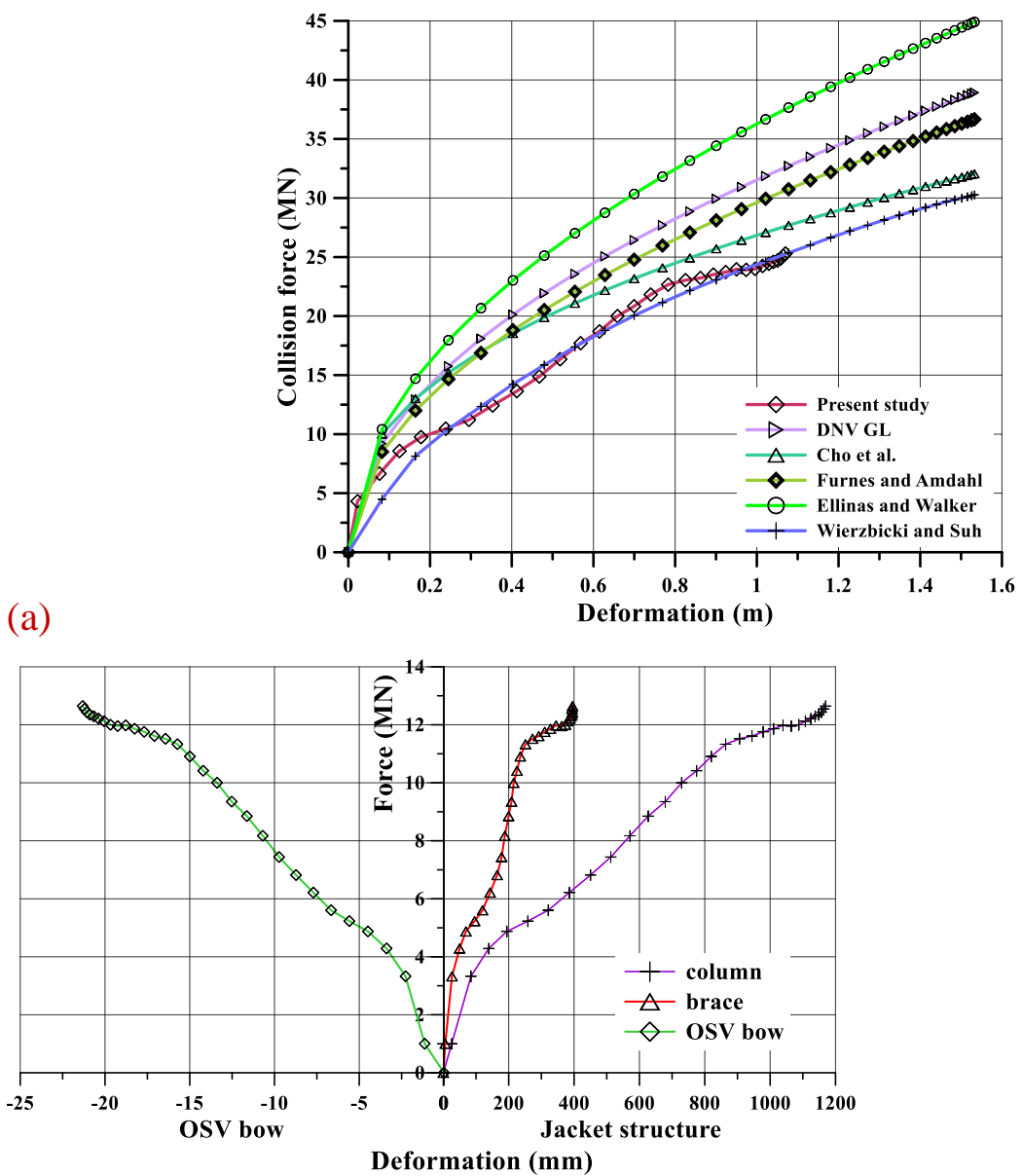

Fig. 21. (a) Results of the validation study, (b) Force-deformation plots of column, brace, and OSV bow structures for collision scenario-11.

\subsection{Exceedance diagrams of damage characteristics}

\subsubsection{Absorbed energies}

By combining the collision frequencies and the absorbed energies calculated for each collision scenario, probability exceedance diagrams are established. Figure 22 (a) 
shows an exceedance diagram of the absorbed energy, considering both column and brace members.

(a)
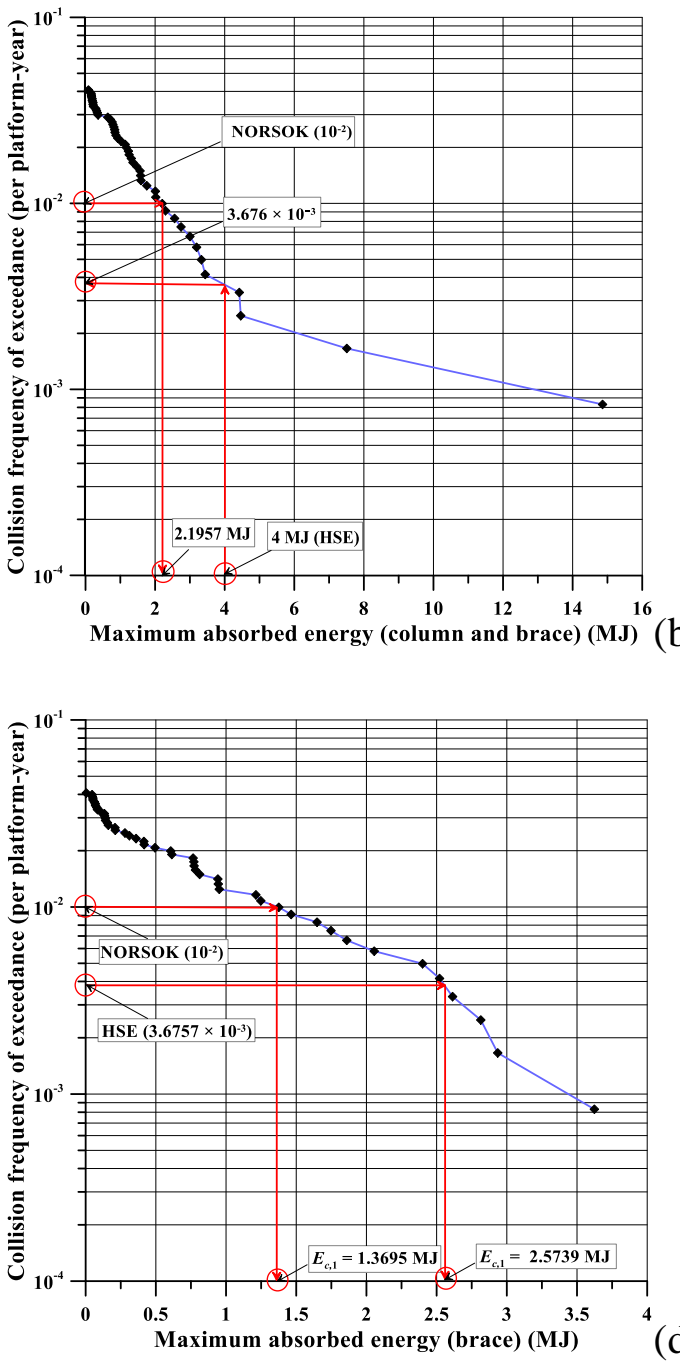

(c)
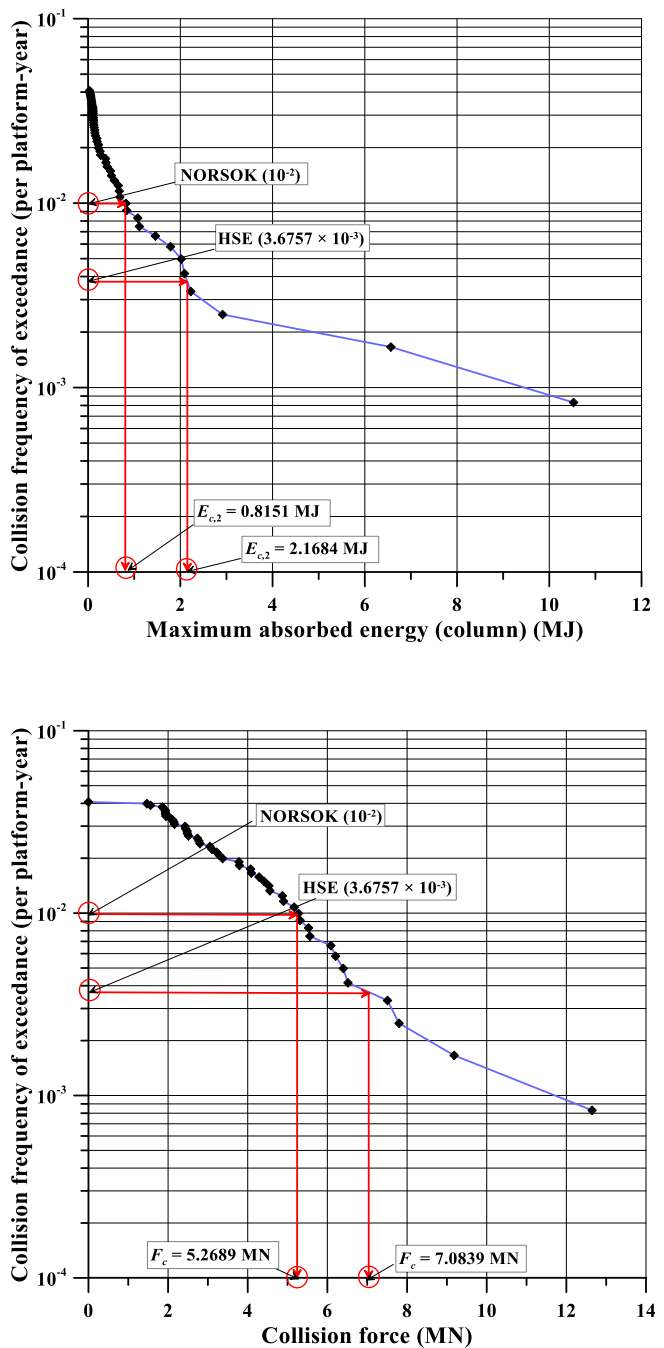

Fig. 22. Exceedance diagrams for the maximum absorbed energies: (a) all members, (b) column, (c) brace, (d) collision force.

Accordingly, corresponding to $4 \mathrm{MJ}$ of absorbed energy recommended by the HSE, the equivalent exceedance probability criterion is found to be $3.6757 \times 10^{-3}$ per platform-year, which is 0.36757 times stricter than NORSOK recommended criteria of $1 \times 10^{-2}$ per platform-year. The same exceedance criterion of HSE is then assigned in the subsequent calculations of design values. Figures 22 (b) and (c) show the exceedance diagrams for the individual column and brace members, respectively. It is interesting to note that the calculated design values of individual columns and brace members are less than considering all members in Fig. 22 (a). Similarly, Fig. 22 (d) provides the design values for the collision force. 


\subsubsection{Local and global deformations}

Table A.3 lists the summary of damage characteristics of the different tubular members measured for 50 collision scenarios. This includes normalized local dent depth and global deformation of the damaged columns as well as brace members. Figure 23 shows the generated exceedance diagrams fitted to these data. It can be seen that the difference between the critical design values calculated based on the NORSOK and HSE acceptance criteria is larger for the bracings as compared to column members. Also, the maximum local denting and global deformation is found to be $0.3363 \mathrm{~m}$ and $0.5643 \mathrm{~m}$, respectively, which satisfies the maximum brace deflection norm of $1 \mathrm{~m}$, recommended by HSE [70].
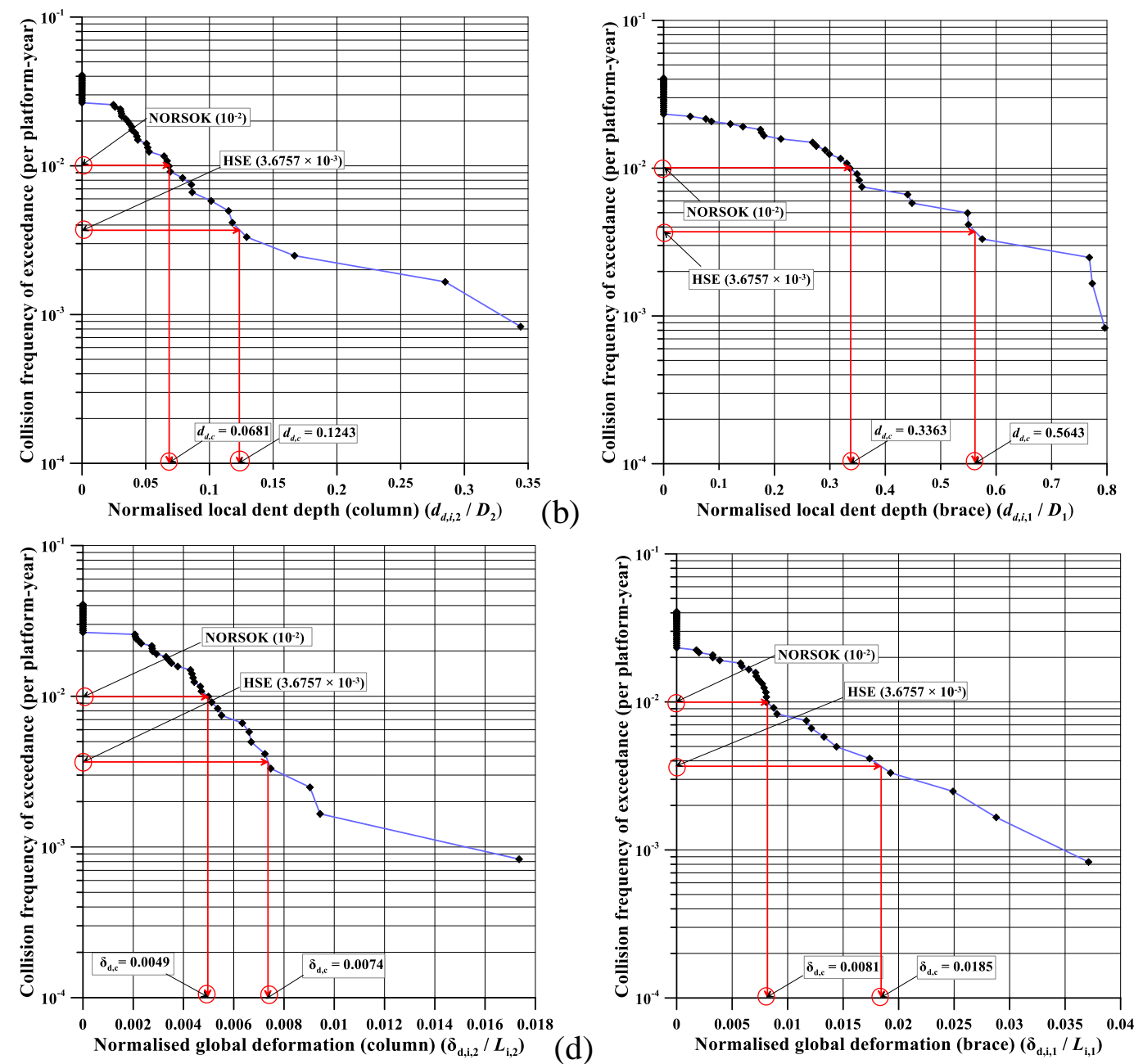

Fig. 23. Exceedance diagrams of normalized deformations: (a) local dent depth (column), (b) local dent depth (brace), (c) global deformation (column), (d) global deformation (brace).

\subsection{Sensitivity study of collision-affecting parameters}

To study the effects of collision-affecting parameters on the structural consequences, we conducted a sensitivity study of the absorbed energy and 
deformation of the column and brace (see Fig. 24, 25, and 26). The input parameters studied include collision velocity, angle, horizontal, and vertical impact location. It is interesting to note that the majority of the collision scenarios fall within the NORSOK criteria, and only a few scenarios exceed the HSE criterion. The number of scenarios exceeding the HSE criterion is comparatively higher for the absorbed energy and brace deformation than the column deformation. Furthermore, among all the collision scenarios, scenarios 11, 42, and 47 dissipate maximum absorbed energies and exceeds both the criteria (see Fig. 24). Although scenario-38 possesses the highest impact energy (see Table A.2), the resulting collision scenario is glancing collision between the bow and column member of the platform, with a considerable residual kinetic energy of the ship. Regarding structural deformation, the same situation can be observed in column members; however, for brace members, scenarios 33, 27, and 20 marks the highest deformations and exceeds the criteria (see Fig. 26).

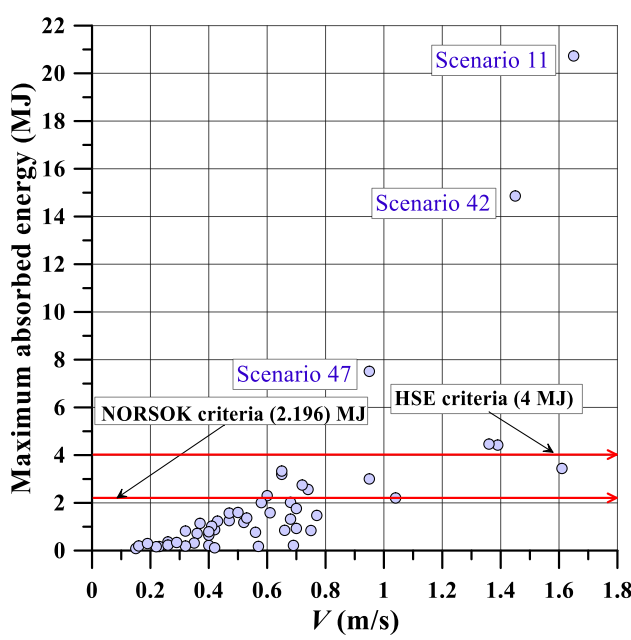

(b)
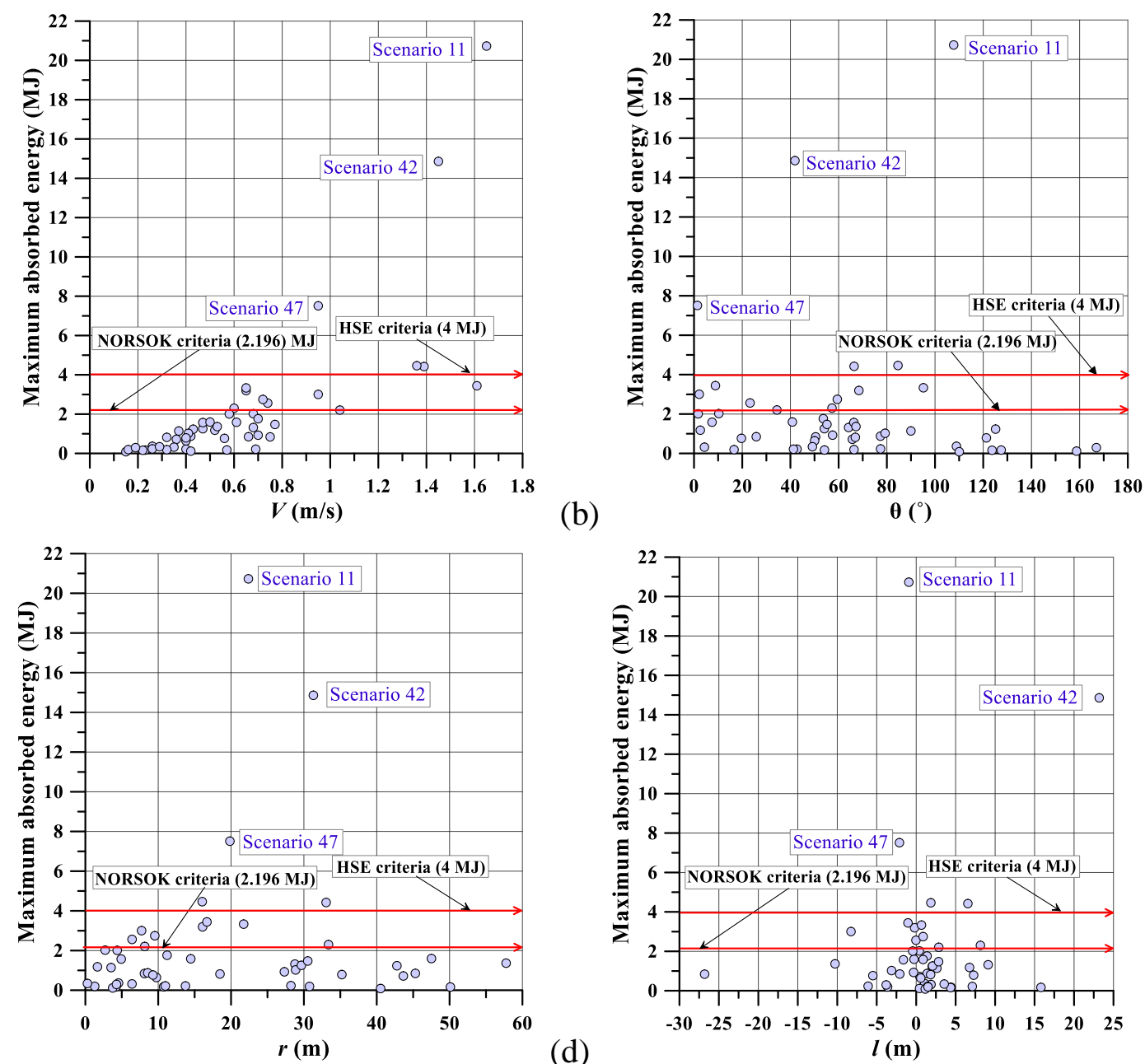

Fig. 24. Sensitivity study of the collision parameters for the maximum absorbed energy: (a) collision velocity, (b) collision angle, (c) horizontal impact location, (d) vertical impact location. 

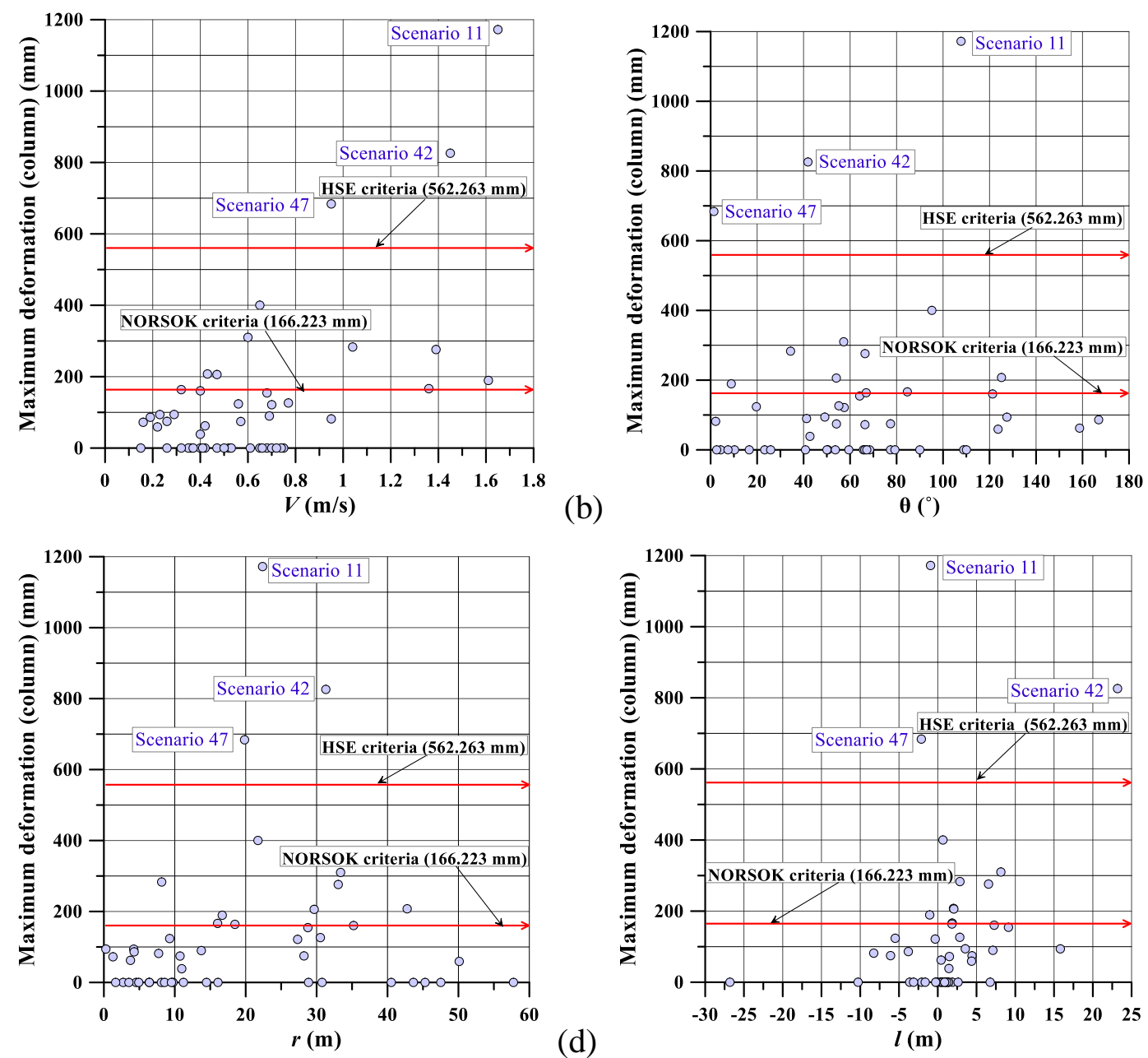

Fig. 25. Sensitivity study of collision parameters for the maximum deformation of columns: (a) collision velocity, (b) collision angle, (c) horizontal impact location, (d) vertical impact location.
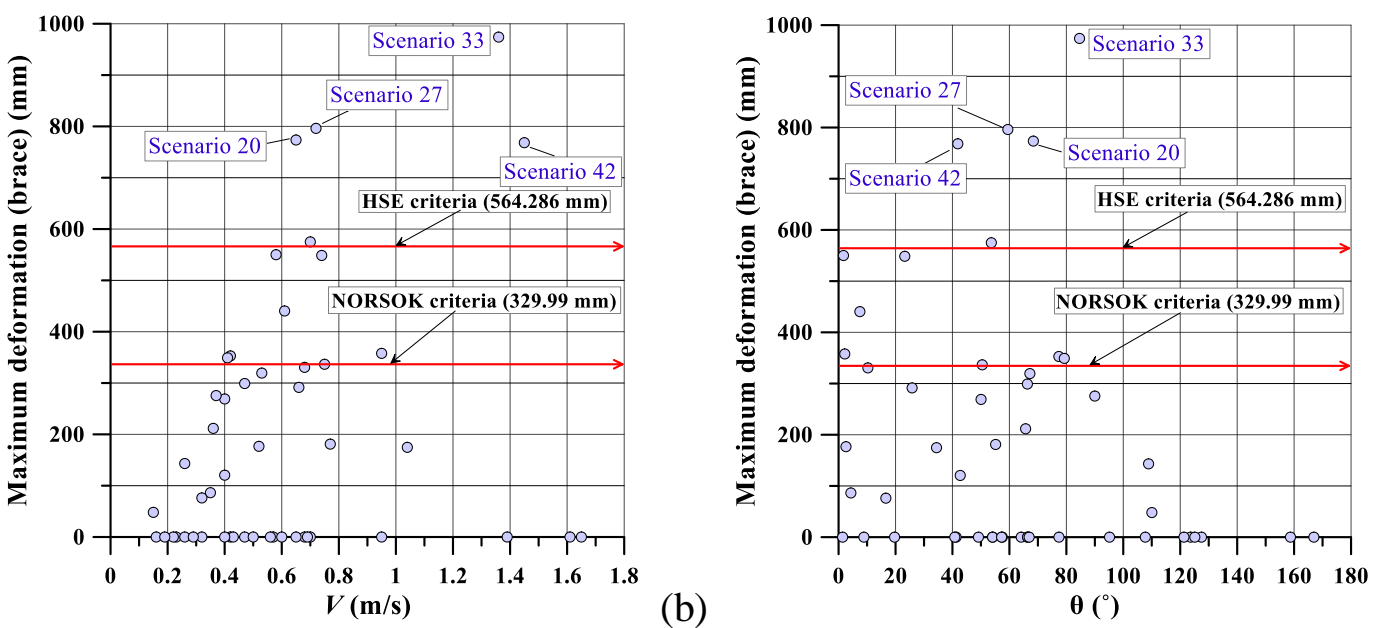
(c)
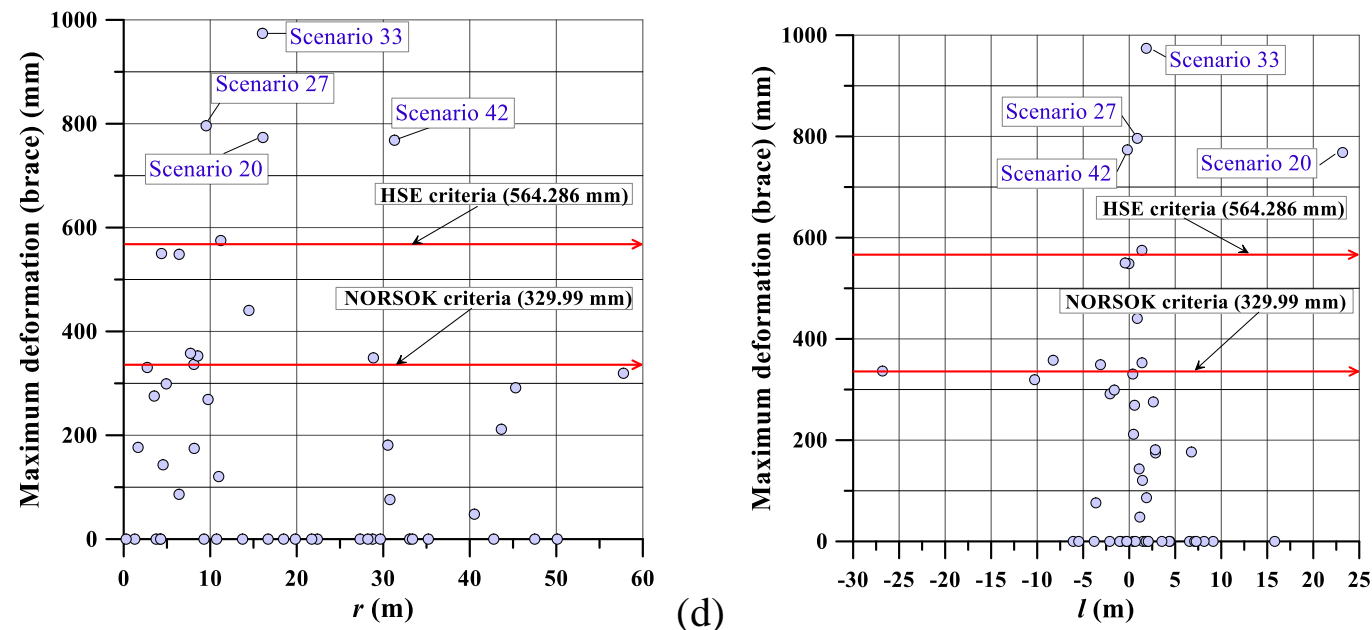

Fig. 26. Sensitivity study of the collision parameters for the maximum deformation of braces: (a) collision velocity, (b) collision angle, (c) horizontal impact location, (d) vertical impact location.

\subsubsection{Exceedance diagrams of repair cost}

Table 5 lists the summary of repair costs and the asset risk of all scenarios. Using Eq.8, the local and global repair cost was calculated, for column and brace members along with their total costs $\left(C_{r}\right)$. The asset risk was obtained by multiplying the collision frequency and the repair cost of each scenario. As expected, the cost of global repair of a damaged member dominates the local repair, in the order of $10^{3}$ USD.

Table 5 Summary of repair costs and asset risks of collision scenarios.

\begin{tabular}{|c|c|c|c|c|c|c|c|c|}
\hline \multirow[b]{2}{*}{$\begin{array}{l}\text { Collision } \\
\text { scenario }\end{array}$} & \multicolumn{3}{|c|}{ Local repair cost $\left(\times 10^{3}\right.$ USD $)$} & \multicolumn{3}{|c|}{$\begin{array}{l}\text { Global repair cost }\left(\times 10^{6}\right. \\
\text { USD })\end{array}$} & \multirow{2}{*}{$\begin{array}{l}\text { Total } \\
\text { cost } \\
\left(C_{r}\right)(\times \\
10^{6} \\
\text { USD })\end{array}$} & \multirow{2}{*}{$\begin{array}{l}\text { Asset } \\
\text { risk } \\
\text { (USD/pl } \\
\text { atform-y } \\
\text { ear) }\end{array}$} \\
\hline & Leg & Brace & Total & Leg & Brace & Total & & \\
\hline 1 & 0 & 5.0240 & 5.0240 & 0 & 0.6675 & 0.6675 & 0.6725 & 558.18 \\
\hline 2 & 0 & 16.9560 & 16.9560 & 0 & 0.6675 & 0.6675 & 0.6844 & 568.08 \\
\hline 3 & 2.1980 & 0 & 2.1980 & 3.1315 & 0 & 3.1315 & 3.1337 & 2601.00 \\
\hline 4 & 0 & 7.5360 & 7.5360 & 0 & 0.6675 & 0.6675 & 0.6750 & 560.26 \\
\hline 5 & 0 & 10.3620 & 10.3620 & 0 & 0.8461 & 0.8461 & 0.8564 & 710.82 \\
\hline 6 & 0 & 4.0820 & 4.0820 & 0 & 0.5738 & 0.5738 & 0.5779 & 479.67 \\
\hline 7 & 0 & 1.8840 & 1.8840 & 0 & 0.8461 & 0.8461 & 0.8479 & 703.79 \\
\hline
\end{tabular}




\begin{tabular}{|c|c|c|c|c|c|c|c|c|}
\hline 8 & 3.7680 & 17.2700 & 20.7240 & 3.1315 & 0.8461 & 3.9776 & 3.9983 & 3318.60 \\
\hline 9 & 14.4440 & 0 & 14.4440 & 2.7743 & 0 & 2.7743 & 2.7887 & 2314.62 \\
\hline 10 & 1.5700 & 0 & 1.5700 & 2.7743 & 0 & 2.7743 & 2.7758 & 2303.93 \\
\hline 11 & 157.9420 & 0 & 157.9420 & 3.1315 & 0 & 3.1315 & 3.2895 & 2730.27 \\
\hline 12 & 0 & 15.7000 & 15.7000 & 0 & 0.5090 & 0.5090 & 0.5247 & 435.51 \\
\hline 13 & 0 & 8.4780 & 8.4780 & 0 & 0.5090 & 0.5090 & 0.5175 & 429.52 \\
\hline 14 & 16.6420 & 0 & 16.6420 & 2.7743 & 0 & 2.7743 & 2.7909 & 2316.44 \\
\hline 15 & 0 & 3.7680 & 3.7680 & 0 & 0.5090 & 0.5090 & 0.5128 & 425.61 \\
\hline 16 & 5.9660 & 0 & 5.9660 & 3.1315 & 0 & 3.1315 & 3.1375 & 2604.13 \\
\hline 17 & 6.5940 & 0 & 6.5940 & 3.1315 & 0 & 3.1315 & 3.1381 & 2604.65 \\
\hline 18 & 4.3960 & 0 & 4.3960 & 3.1315 & 0 & 3.1315 & 3.1359 & 2602.82 \\
\hline 19 & 16.3280 & 17.2700 & 33.5980 & 2.7686 & 0.6675 & 3.4361 & 3.4697 & 2879.81 \\
\hline 20 & 0.0000 & 23.8640 & 31.7140 & 2.7686 & 0.5090 & 3.2776 & 3.3093 & 2746.72 \\
\hline 21 & 14.1300 & 0 & 14.1300 & 3.1315 & 0 & 3.1315 & 3.1457 & 2610.90 \\
\hline 22 & 0 & 8.7920 & 8.7920 & 0 & 0.5090 & 0.5090 & 0.5178 & 429.78 \\
\hline 23 & 0 & 6.5940 & 6.5940 & 0 & 0.5090 & 0.5090 & 0.5156 & 427.96 \\
\hline 24 & 0 & 0.3140 & 0.3140 & 0 & 0.6675 & 0.6675 & 0.6678 & 554.27 \\
\hline 25 & 1.8840 & 13.1880 & 15.0720 & 2.7686 & 0.6675 & 3.4361 & 3.4511 & 2864.43 \\
\hline 26 & 5.3380 & 0 & 5.3380 & 3.1315 & 0 & 3.1315 & 3.1369 & 2603.61 \\
\hline 27 & 0 & 22.2940 & 22.2940 & 0 & 0.2720 & 0.2720 & 0.2943 & 244.28 \\
\hline 28 & 14.4440 & 0 & 14.4440 & 3.1315 & 0 & 3.1315 & 3.1460 & 2611.16 \\
\hline 29 & 0 & 28.2600 & 28.2600 & 0 & 0.5090 & 0.5090 & 0.5373 & 2751.41 \\
\hline 30 & 4.3960 & 0 & 4.3960 & 3.1315 & 0 & 3.1315 & 3.1359 & 2602.82 \\
\hline 31 & 0 & 20.4100 & 20.4100 & 0 & 0.5090 & 0.5090 & 0.5294 & 439.42 \\
\hline 32 & 0 & 8.7920 & 8.7920 & 0 & 0.6675 & 0.6675 & 0.6763 & 561.30 \\
\hline 33 & 10.0480 & 36.7380 & 46.7860 & 2.7743 & 0.5090 & 3.2833 & 3.3301 & 2763.94 \\
\hline 34 & 8.1640 & 0 & 8.1640 & 3.1315 & 0 & 3.1315 & 3.1397 & 2605.95 \\
\hline 35 & 6.2800 & 0 & 6.2800 & 3.1315 & 0 & 3.1315 & 3.1378 & 2604.39 \\
\hline 36 & 28.2600 & 0 & 28.2600 & 3.1315 & 0 & 3.1315 & 3.1598 & 2622.63 \\
\hline 37 & 21.6660 & 6.2800 & 27.9460 & 2.7686 & 0.5738 & 3.3424 & 3.3704 & 2797.39 \\
\hline 38 & 41.7620 & 0 & 41.7620 & 2.7743 & 0 & 2.7743 & 2.8160 & 2337.29 \\
\hline 39 & 1.5700 & 10.9900 & 12.5600 & 2.7743 & 0.6675 & 3.4417 & 3.4543 & 2867.06 \\
\hline 40 & 18.8400 & 0 & 18.8400 & 3.1315 & 0 & 3.1315 & 3.1504 & 2614.81 \\
\hline 41 & 8.4780 & 0 & 8.4780 & 3.1315 & 0 & 3.1315 & 3.1400 & 2606.21 \\
\hline 42 & 134.3920 & 39.8780 & 174.2700 & 2.7743 & 0.2720 & 3.0463 & 3.2205 & 2673.05 \\
\hline
\end{tabular}




\begin{tabular}{lllllllll}
43 & 75.9880 & 0 & 75.9880 & 0 & 0.5090 & 0.5090 & 0.5850 & 485.55 \\
44 & 27.6320 & 0 & 27.6320 & 2.7743 & 0 & 2.7743 & 2.8019 & 2325.56 \\
45 & 9.7340 & 0 & 9.7340 & 2.7743 & 0 & 2.7743 & 2.7840 & 2310.71 \\
46 & 0 & 36.4240 & 36.4240 & 0 & 0.5090 & 0.5090 & 0.5454 & 452.71 \\
47 & 64.3700 & 0 & 64.3700 & 3.1315 & 0 & 3.1315 & 3.1959 & 2652.60 \\
48 & 27.3180 & 0 & 27.3180 & 3.1315 & 0 & 3.1315 & 3.1589 & 2621.85 \\
49 & 0 & 14.7580 & 14.7580 & 0 & 0.6675 & 0.6675 & 0.6822 & 566.26 \\
50 & 18.2120 & 140.0440 & 158.2560 & 2.7743 & 0.6675 & 3.4417 & 3.6000 & 2987.99 \\
\hline
\end{tabular}

Figure 27 provides the exceedance diagrams of local, global, and total repair costs for columns and braces separately. In general, it can be observed that the repair cost of the column is higher than the brace member because additional steel material is required to replace the heavier and larger column members as compared to brace members. On comparing NORSOK and HSE criteria, the calculated repair costs are the same for the globally damaged column and brace member [see Fig. 27 (c) and (d)]; however, an $8.44 \%$ increase of repair cost using HSE criteria is found considering all the members [see Fig. 27 (f)]. On the other hand, for the local repair cost of either column, brace, or both, a significant increase (approximately two times) using HSE criteria can be found. Because the global repair cost is approximately in the order of 1000 times higher than the local repair costs, the effects of local cost to the total repair cost become insignificant, as shown in Fig. 27 (g).

(a)

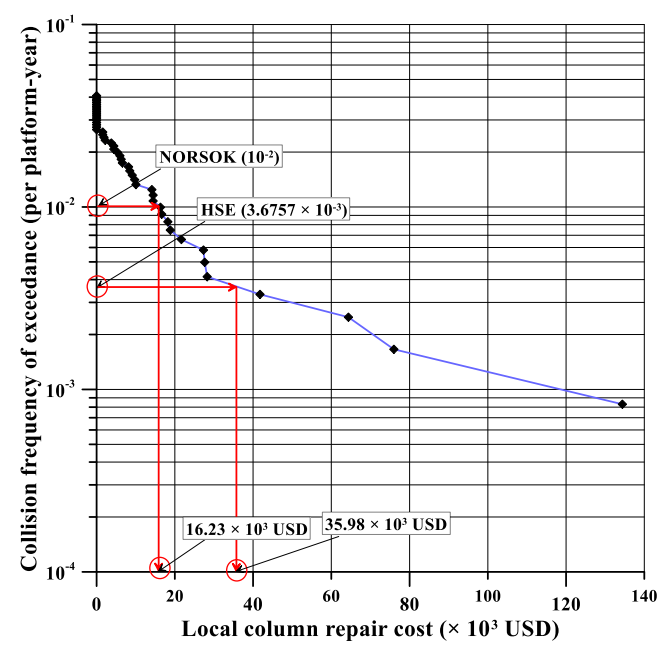

(b)

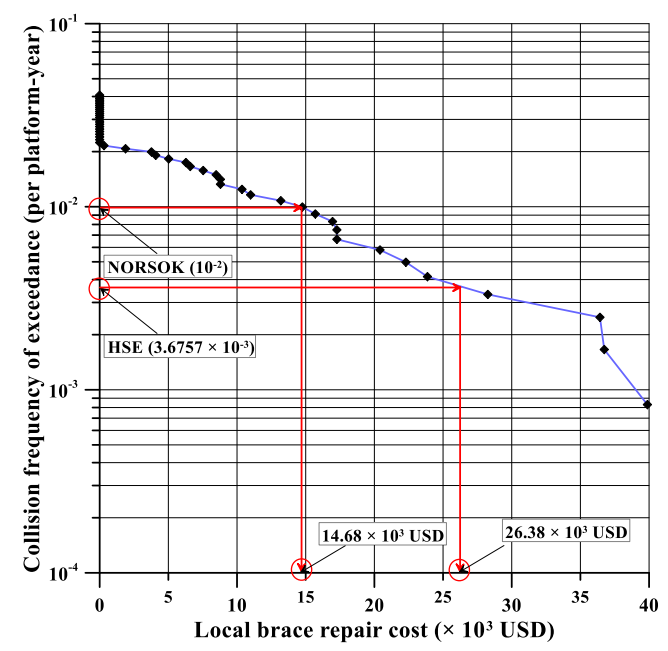


(c)

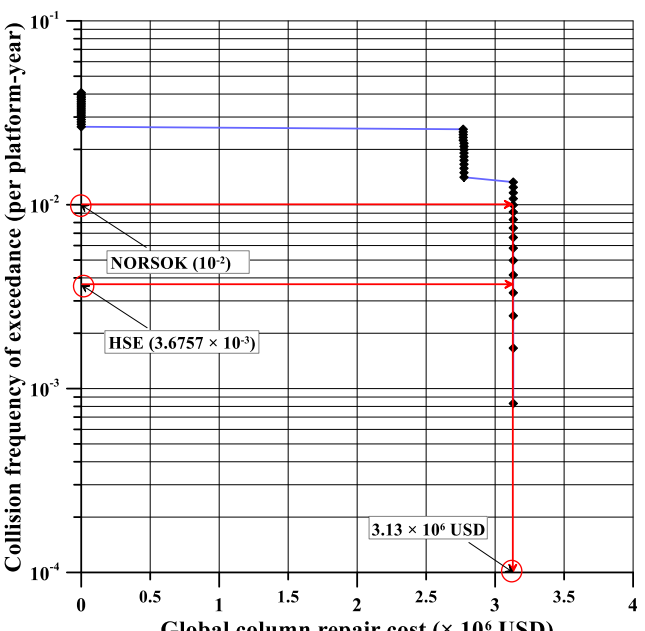

Global column repair cost $\left(\times 10^{6} \mathrm{USD}\right)$

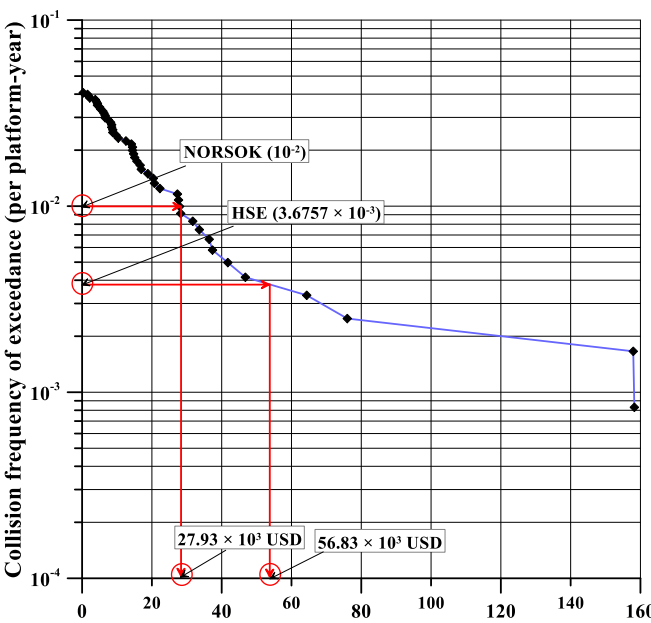

(e)

Total local repair cost $\left(\times 10^{3}\right.$ USD $)$

(f)

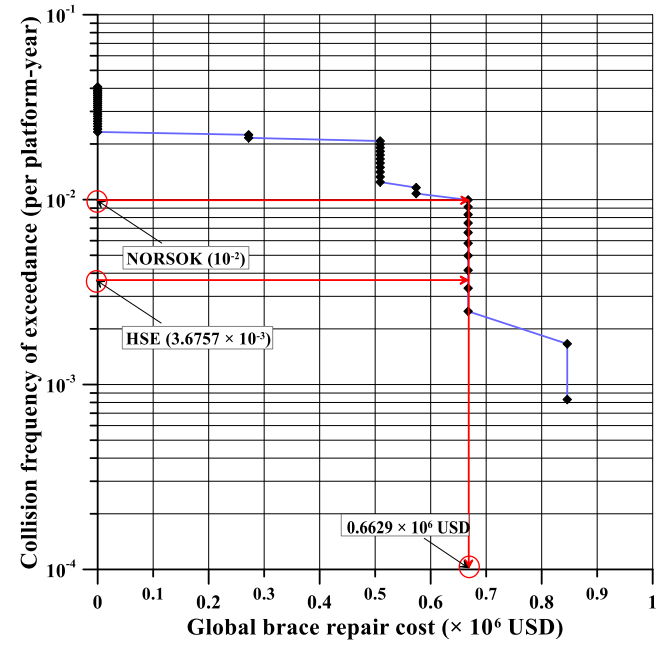

(d)

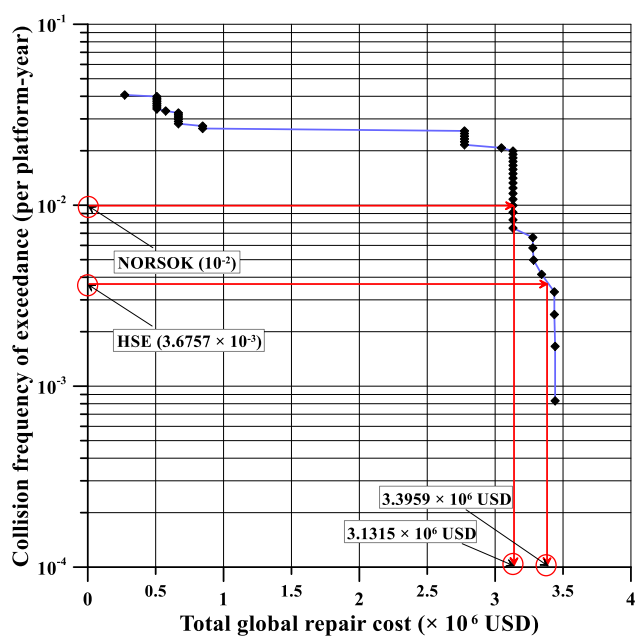

$(\mathrm{g})$

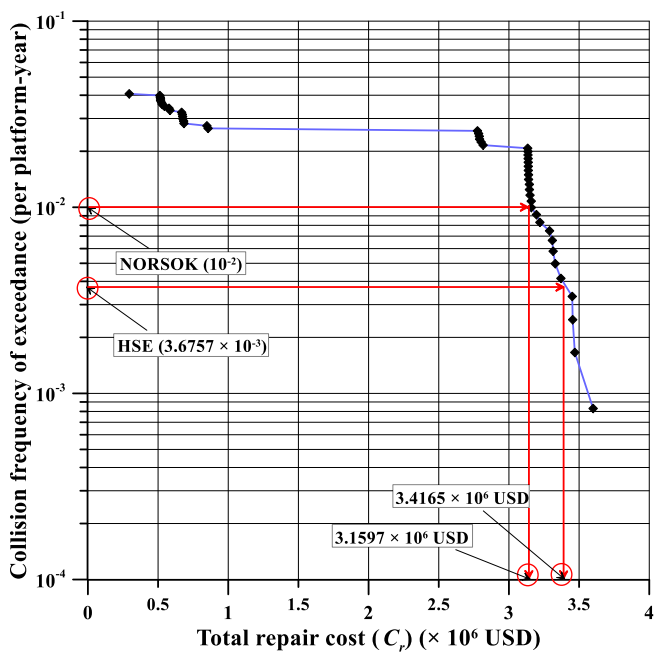

Fig. 27. Exceedance diagrams for different repair costs: (a) local column, (b) local brace, (c) global column, (d) global brace, (e) total local, (f) total global, (g) total cost.

Table 6 provides a summary of the design values of risks based on the NORSOK and HSE criteria calculated separately for the structural consequences and repair costs. 
As expected, it can be seen that the calculated risk for all design parameters is reduced with the use of stricter acceptance criteria of HSE. However, a stricter acceptance criterion may draw large collision load leading to higher consequences in terms of structural deformation, absorbed energy, and repair costs, thereby increases the risk. This is confirmed by comparing the values of the percentage decrease in the risk of various parameters and the exceedance criteria. Accordingly, the maximum reduction of risk is found to be $60.26 \%$, for repair costs, which is close to $63.24 \%$ reduction in the actual acceptance criteria. On the other hand, the reduction in energy absorbed by the column is found to be only $2.21 \%$. Hence, considering economic factors, a platform owner or designer may prudently select HSE criteria, with a necessary increase in structural requirements. Further, one may reduce the repair cost and structural consequences by performing a cost-benefit analysis by redesigning the platform and collision mitigation measures.

Table 6 Summary of risk values of different design parameters.

\begin{tabular}{|c|c|c|c|c|c|}
\hline $\begin{array}{l}\text { Sl. } \\
\text { no. }\end{array}$ & Design parameters & $\begin{array}{l}\text { Unit (per } \\
\text { platform-year) }\end{array}$ & $\begin{array}{l}\text { NORSOK } \\
\text { criteria } \\
\left(10^{-2} \text { per }\right. \\
\text { platform-y } \\
\text { ear })\end{array}$ & $\begin{array}{l}\text { HSE criteria } \\
\left(3.6757 \times 10^{-3}\right. \\
\text { per } \\
\text { platform-year })\end{array}$ & $\begin{array}{l}\text { Percenta } \\
\text { ge } \\
\text { reduction } \\
\text { of risk } \\
(\%)\end{array}$ \\
\hline 1 & $\begin{array}{l}\text { Energy absorbed } \\
\text { (column) }\left(E_{c, 2}\right)\end{array}$ & MJ & $8.15 \times 10^{-3}$ & $7.97 \times 10^{-3}$ & 2.21 \\
\hline 2 & $\begin{array}{l}\text { Energy absorbed } \\
\text { (brace) }\left(E_{c, 1}\right)\end{array}$ & MJ & $1.37 \times 10^{-2}$ & $9.46 \times 10^{-3}$ & 30.92 \\
\hline 3 & Collision force $\left(F_{c}\right)$ & $\mathrm{MN}$ & $5.27 \times 10^{-2}$ & $2.6 \times 10^{-2}$ & 50.58 \\
\hline 4 & $\begin{array}{l}\text { Local dent depth } \\
\text { (column) }\left(\delta_{d, c, 2}\right)\end{array}$ & $\mathrm{m}$ & $6.81 \times 10^{-4}$ & $4.57 \times 10^{-4}$ & 32.91 \\
\hline 5 & $\begin{array}{l}\text { Local dent depth } \\
\text { (brace) }\left(\delta_{d, c, 1}\right)\end{array}$ & $\mathrm{m}$ & $3.36 \times 10^{-3}$ & $2.7 \times 10^{-3}$ & 38.32 \\
\hline 6 & $\begin{array}{l}\text { Global deformation } \\
\text { (column) }\left(d_{d, c, 2}\right)\end{array}$ & $\mathrm{m}$ & $4.90 \times 10^{-5}$ & $2.72 \times 10^{-5}$ & 44.49 \\
\hline 7 & $\begin{array}{l}\text { Global deformation } \\
\text { (brace) }\left(d_{d, c, 1}\right)\end{array}$ & $\mathrm{m}$ & $8.90 \times 10^{-5}$ & $6.8 \times 10^{-5}$ & 23.59 \\
\hline
\end{tabular}


$8 \quad$ Total repair cost $\left(C_{r}\right) \quad$ million USD $\quad 3.16 \times 10^{-2} \quad 1.26 \times 10^{-2} \quad 60.26$

\section{Summary}

The main focus of the study is to enhance the safety of offshore platforms against ship collision accidents using a risk-based design process. An advanced procedure for the QRA of offshore platforms in collisions with incoming supply vessels was developed. A practical demonstration of the developed method has been carried out with an illustrative example, considering collisions between an OSV and an offshore jacket platform.

Based on a set of fifty collision scenarios selected using the probabilistic sampling method, vessel motion analysis was carried out to determine collision loads. Subsequently, an extensive structural crashworthiness analysis was performed using modern computational techniques, which includes the dynamic material properties (fracture strain, yield strength, and strain rate), surrounding water, and structural deformations in both the vessel and platform. The resultant damage characteristics measured include absorbed energy, collision forces, local denting, and global deformation of the tubular members.

A sensitivity study was performed to study the effect of the collision-influencing parameters on the damage characteristics such as the absorbed energy and the structural deformation. The probability exceedance diagrams were established for different damage characteristics, and design parameters were compared using NORSOK and HSE acceptance criteria. It was shown that for the platform under-study, a lower value of absorbed energy and structural deformation is appropriate as compared to the recommended values suggested by HSE.

Further, a simplified repair cost model has been utilized due to the lack of literature stemming from confidential nature. Besides, the development of the cost model is complex, which involves a large number of variables, and the final decision is taken solely by the platform owners or the design engineers.

The repair cost was estimated for both local denting and global damage of tubular members. Asset risk was derived in terms of exceedance diagrams, and the design values of repair cost were determined and compared based on the NORSOK and HSE acceptance criteria.

It is believed that the developed exceedance diagrams of consequences would aid offshore platform owners and designers in their decision-making process of structural requirements and repair costs. Accordingly, a cost-benefit analysis can be carried out, and further actions for collision mitigation measures such as redesigning could be undertaken for the offshore platform.

\section{Conclusions}

The main focus of the study was on how to enhance the safety of offshore platforms against ship collision accidents using a risk-based design process. From the results 
obtained, the following conclusions can be drawn:

1. A novel risk-based methodology was proposed to perform a quantitative collision risk assessment of OSV to an offshore jacket platform.

2. The severity of collision consequences was measured in terms of structural damage and repair costs using extensive nonlinear structural crashworthiness analysis of fifty collision scenarios.

3. Recommended industry practices and relevant guidelines were followed to determine the design values for various key indicators of the collision risk.

4. The percentage reduction of risk with stricter acceptance criteria is different for different consequence parameters, and one may choose the best criteria for a platform based on the cost-benefit analysis.

5. The methodologies and insights developed in this research will be practically useful for assessing ship collision risks (quantitatively) to a specific offshore platform.

Following the risk methodology, future works are recommended for many perspectives.

- The proposed method can be applied to a real offshore platform instead of the hypothetical model used in the illustrative example. Structures such as fenders and boat landings attached to the platform can be considered in crashworthiness analysis. Also, the increased strength and thickness with the presence of joint cans and brace stubs, welding, and residual stress at the joints could be modelled more accurately.

- Following a similar methodology, one may perform the risk assessment for other collision scenarios, e.g., during transfer operations or vessel leaving the platform, where stern and side end of the ship impact with the platform. Also, ship collisions to other types of offshore platforms such as offshore wind turbines (OWT), semisubmersible, FPSO, and jack up can be studied.

- Risk-based acceptance criteria have been used in this study to determine the repair action of damaged members. Alternatively, one may also be interested in the global integrity of the platform using pushover analysis to measure the residual load-carrying capacity to specify repair action and reinstate oil production.

- In the illustrative example, collision accidents during 1970-2014 were considered for calculating collision frequency. One may merge recent accident data and conduct the QRA following a similar procedure.

\section{Acknowledgments}

This research was undertaken at the Korea Ship and Offshore Research Institute (KOSORI), ICASS (International Centre for Advanced Safety Studies) at Pusan National University, which has been a Lloyd's Register Foundation (LRF) Research Centre of Excellence since 2008. The support of Dr. Serdar Turgut Ince and Dr. José Manuel Cabrera-Miranda are greatly acknowledged. 


\section{Appendix.}

Table A.1 Principal dimension and scantling details of the OSV bow model.

\begin{tabular}{|c|c|}
\hline Particulars & Dimensions \\
\hline Bow height & $14.9 \mathrm{~mm}$ \\
\hline Bulb height & $9.1 \mathrm{~m}$ \\
\hline Stem height & $5.8 \mathrm{~m}$ \\
\hline Bow breadth & $17.04 \mathrm{~m}$ \\
\hline Forecastle hull plate thickness & $12 \mathrm{~mm}$ \\
\hline Bulb hull plate thickness & $11 \mathrm{~mm}$ \\
\hline Transverse frame thickness & $10 \mathrm{~mm}$ \\
\hline $\begin{array}{l}\text { Distance between transverse frames (in } \\
\text { the bulb) }\end{array}$ & $600 \mathrm{~mm}$ \\
\hline $\begin{array}{l}\text { Distance between transverse frames (in } \\
\text { the forecastle) }\end{array}$ & $1.8 \mathrm{~m}$ \\
\hline $\begin{array}{l}\text { Protrude of forecastle from the bulb } \\
\text { (along bow direction) }\end{array}$ & $35 \mathrm{~mm}$ \\
\hline $\begin{array}{l}\text { Protrude of forecastle from the bulb } \\
\text { (along port/starboard direction) }\end{array}$ & $6.5 \mathrm{~m}$ \\
\hline Bulb radius (along centerline) & $2 \mathrm{~m}$ \\
\hline First deck plate thickness & $7.5 \mathrm{~mm}$ \\
\hline Second deck plate thickness & $7 \mathrm{~mm}$ \\
\hline Third deck plate thickness & $9 \mathrm{~mm}$ \\
\hline Bulbous deck plate thickness & $12 \mathrm{~mm}$ \\
\hline Transverse frame plate thickness & $7 \mathrm{~mm}$ \\
\hline $\begin{array}{l}\text { Transverse stiffener plate thickness (bulb } \\
\text { and forecastle) }\end{array}$ & $10 \mathrm{~mm}$ \\
\hline
\end{tabular}

Table A.2 Summary of collision load scenarios as obtained from time-domain vessel motion analysis.

\begin{tabular}{llllll}
\hline $\begin{array}{l}\text { Scenario } \\
\text { number }\end{array}$ & $\begin{array}{l}\text { Velocity, } \\
V(\mathrm{~m} / \mathrm{s})\end{array}$ & $\begin{array}{l}\text { Angle, } \\
\left({ }^{\circ}\right)\end{array}$ & $\begin{array}{l}\text { Vertical } \\
\text { impact } \\
\text { location, } \\
l(\mathrm{~m})\end{array}$ & $\begin{array}{l}\text { Horizontal } \\
\text { impact } \\
\text { location, } \\
(\mathrm{m})\end{array}$ & $\begin{array}{l}\text { Initial } \\
\text { kinetic } \\
\text { energy, } \\
E(\mathrm{MJ})\end{array}$ \\
\hline 1 & 0.36 & 65.69 & 0.47 & 43.65 & 0.63 \\
2 & 0.68 & 10.29 & 0.39 & 2.72 & 2.76 \\
3 & 0.57 & 54.12 & 4.42 & 10.74 & 1.66 \\
4 & 0.35 & 4.32 & 1.88 & 6.40 & 0.74 \\
\hline
\end{tabular}




\begin{tabular}{|c|c|c|c|c|c|}
\hline 5 & 0.75 & 50.46 & -26.81 & 8.11 & 2.91 \\
\hline 6 & 0.26 & 108.88 & 1.08 & 4.55 & 0.32 \\
\hline 7 & 0.32 & 16.61 & -3.62 & 30.77 & 0.61 \\
\hline 8 & 0.74 & 23.25 & -0.03 & 6.41 & 3.21 \\
\hline 9 & 0.68 & 64.14 & 9.12 & 28.77 & 2.26 \\
\hline 10 & 0.23 & 127.45 & 15.81 & 4.21 & 0.27 \\
\hline 11 & 1.65 & 107.73 & -0.93 & 22.38 & 13.18 \\
\hline 12 & 0.70 & 53.65 & 1.38 & 11.22 & 2.54 \\
\hline 13 & 0.42 & 77.37 & 1.39 & 8.56 & 0.84 \\
\hline 14 & 0.70 & 57.49 & -0.33 & 27.32 & 2.46 \\
\hline 15 & 0.40 & 42.73 & 1.44 & 10.98 & 0.87 \\
\hline 16 & 0.26 & 77.40 & -6.09 & 28.22 & 0.31 \\
\hline 17 & 0.42 & 158.72 & 0.43 & 3.75 & 1.03 \\
\hline 18 & 0.22 & 123.65 & 4.36 & 50.11 & 0.26 \\
\hline 19 & 1.39 & 66.42 & 6.55 & 33.05 & 9.45 \\
\hline 20 & 0.65 & 68.41 & -0.20 & 16.09 & 2.05 \\
\hline 21 & 0.43 & 125.13 & 2.03 & 42.77 & 0.94 \\
\hline 22 & 0.66 & 25.82 & -2.08 & 45.30 & 2.54 \\
\hline 23 & 0.40 & 50.04 & 0.58 & 9.75 & 0.85 \\
\hline 24 & 0.15 & 110.04 & 1.15 & 40.53 & 0.11 \\
\hline 25 & 0.37 & 90.00 & 2.62 & 3.53 & 0.66 \\
\hline 26 & 0.16 & 66.39 & 1.50 & 1.28 & 0.12 \\
\hline 27 & 0.72 & 59.45 & 0.88 & 9.53 & 2.63 \\
\hline 28 & 0.56 & 19.67 & -5.49 & 9.28 & 1.84 \\
\hline 29 & 0.95 & 2.17 & -8.26 & 7.72 & 5.42 \\
\hline 30 & 0.19 & 166.94 & -3.80 & 4.27 & 0.21 \\
\hline 31 & 0.61 & 7.48 & 0.88 & 14.47 & 2.21 \\
\hline 32 & 0.41 & 79.28 & -3.12 & 28.86 & 0.79 \\
\hline 33 & 1.36 & 84.63 & 1.86 & 16.04 & 8.70 \\
\hline 34 & 0.32 & 66.93 & 1.83 & 18.48 & 0.51 \\
\hline 35 & 0.29 & 49.12 & 3.55 & 0.28 & 0.44 \\
\hline 36 & 0.65 & 95.17 & 0.67 & 21.73 & 1.98 \\
\hline 37 & 1.04 & 34.40 & 2.86 & 8.15 & 6.01 \\
\hline 38 & 1.61 & 8.89 & -1.04 & 16.69 & 15.38 \\
\hline 39 & 0.52 & 2.60 & 6.76 & 1.66 & 1.62 \\
\hline
\end{tabular}




\begin{tabular}{llllll}
\hline 40 & 0.47 & 54.07 & 2.07 & 29.66 & 1.13 \\
41 & 0.69 & 41.27 & 7.11 & 13.74 & 2.60 \\
42 & 1.45 & 41.88 & 23.19 & 31.30 & 11.30 \\
43 & 0.47 & 66.32 & -1.62 & 4.92 & 1.09 \\
44 & 0.60 & 57.25 & 8.14 & 33.38 & 1.84 \\
45 & 0.40 & 121.31 & 7.28 & 35.21 & 0.81 \\
46 & 0.53 & 67.19 & -10.28 & 57.76 & 1.40 \\
47 & 0.95 & 1.41 & -2.12 & 19.84 & 5.44 \\
48 & 0.50 & 40.81 & -0.27 & 47.51 & 1.37 \\
49 & 0.58 & 1.72 & -0.44 & 4.37 & 2.01 \\
50 & 0.77 & 55.16 & 2.84 & 30.53 & 3.05 \\
\hline
\end{tabular}

Table A.3 Summary of local and global damage characteristics of tubular members obtained from crashworthiness analysis.

\begin{tabular}{|c|c|c|c|c|c|}
\hline \multirow[t]{2}{*}{$\begin{array}{l}\text { Collision } \\
\text { scenario }\end{array}$} & \multirow[t]{2}{*}{$\begin{array}{l}\text { Damaged } \\
\text { member } \\
\text { (ID) }\end{array}$} & \multicolumn{2}{|c|}{$\begin{array}{l}\text { Normalized } \\
\text { maximum local } \\
\text { dent depth, } \\
d_{d, i, j} / D_{j}\end{array}$} & \multicolumn{2}{|c|}{$\begin{array}{l}\text { Normalized maximum } \\
\text { global deformation, } \\
\delta_{d, i, j} / L_{m, j}\end{array}$} \\
\hline & & Column & Brace & Column & Brace \\
\hline 1 & $\mathrm{RD}_{1}$ & 0 & 0.2116 & 0 & $7.39 \times 10^{-3}$ \\
\hline 2 & $\mathrm{LD}_{1}$ & 0 & 0.3305 & 0 & $8.04 \times 10^{-3}$ \\
\hline 3 & $\mathrm{~L}_{5}$ & 0.0309 & 0 & $2.22 \times 10^{-3}$ & 0 \\
\hline 4 & $\mathrm{RD}_{1}$ & 0 & 0.0862 & 0 & $3.25 \times 10^{-3}$ \\
\hline \multirow[t]{2}{*}{5} & $\mathrm{RD}_{5}$ & 0 & 0.3365 & 0 & $9.04 \times 10^{-3}$ \\
\hline & $\mathrm{LD}_{1}$ & 0 & 0.1025 & 0 & $3.33 \times 10^{-3}$ \\
\hline 6 & $\mathrm{H}_{6}$ & 0 & 0.1431 & 0 & $3.26 \times 10^{-3}$ \\
\hline 7 & $\mathrm{RD}_{5}$ & 0 & 0.0761 & 0 & $1.78 \times 10^{-3}$ \\
\hline \multirow[t]{2}{*}{8} & $\mathrm{LD}_{5}, \mathrm{~L}_{8}$ & 0.0430 & 0.5485 & $3.40 \times 10^{-3}$ & $1.02 \times 10^{-2}$ \\
\hline & $\mathrm{RD}_{5}$ & 0 & 0.3126 & 0 & $1.06 \times 10^{-2}$ \\
\hline 9 & $\mathrm{~L}_{4}$ & 0.0644 & 0 & $5.36 \times 10^{-3}$ & 0 \\
\hline 10 & $\mathrm{~L}_{4}$ & 0.0391 & 0 & $4.34 \times 10^{-3}$ & 0 \\
\hline 11 & $\mathrm{~L}_{5}$ & 0.4884 & 0 & $1.74 \times 10^{-2}$ & 0 \\
\hline 12 & $\mathrm{H}_{5}$ & 0 & 0.5751 & 0 & $1.93 \times 10^{-2}$ \\
\hline 13 & $\mathrm{H}_{5}$ & 0 & 0.3528 & 0 & $1.17 \times 10^{-2}$ \\
\hline 14 & $\mathrm{~L}_{4}$ & 0.0506 & 0 & $5.12 \times 10^{-3}$ & 0 \\
\hline
\end{tabular}




\begin{tabular}{|c|c|c|c|c|c|}
\hline 15 & $\mathrm{H}_{5}$ & 0 & 0.1205 & 0 & $5.76 \times 10^{-3}$ \\
\hline 16 & $\mathrm{~L}_{4}$ & 0.0311 & 0 & $2.77 \times 10^{-3}$ & 0 \\
\hline 17 & $\mathrm{~L}_{8}$ & 0.0259 & 0 & $2.12 \times 10^{-3}$ & 0 \\
\hline 18 & $\mathrm{~L}_{1}$ & 0.02466 & 0 & $2.09 \times 10^{-3}$ & 0 \\
\hline 19 & $\mathrm{~L}_{1}, \mathrm{LD}_{1}$ & 0.1150 & 0.4482 & $6.69 \times 10^{-3}$ & $6.13 \times 10^{-3}$ \\
\hline 20 & $\mathrm{H}_{8}, \mathrm{~L}_{3}$ & 0.0437 & 0.7734 & $3.33 \times 10^{-3}$ & $2.49 \times 10^{-2}$ \\
\hline 21 & $\mathrm{~L}_{5}$ & 0.08647 & 0 & $4.71 \times 10^{-3}$ & 0 \\
\hline \multirow[t]{2}{*}{22} & $\mathrm{H}_{8}$ & 0 & 0.2914 & 0 & $8.09 \times 10^{-3}$ \\
\hline & $\mathrm{LD}_{4}$ & 0 & 0.1167 & 0 & $3.31 \times 10^{-3}$ \\
\hline 23 & $\mathrm{H}_{5}$ & 0 & 0.2689 & 0 & $8.09 \times 10^{-3}$ \\
\hline 24 & $\mathrm{LD}_{1}$ & 0 & 0.0482 & 0 & $2.01 \times 10^{-3}$ \\
\hline 25 & $\mathrm{LD}_{1}, \mathrm{~L}_{8}$ & 0.0305 & 0.2755 & $2.83 \times 10^{-3}$ & $3.88 \times 10^{-3}$ \\
\hline 26 & $\mathrm{~L}_{8}$ & 0.0301 & 0 & $2.31 \times 10^{-3}$ & 0 \\
\hline 27 & $\mathrm{H}_{8}$ & 0 & 0.7961 & 0 & $5.34 \times 10^{-2}$ \\
\hline 28 & $\mathrm{~L}_{5}$ & 0.0515 & 0 & $4.43 \times 10^{-3}$ & 0 \\
\hline \multirow{2}{*}{29} & $\mathrm{LD}_{1}$ & 0 & 0.3578 & 0 & $5.88 \times 10^{-3}$ \\
\hline & $\mathrm{H}_{5}$ & 0 & 0.0817 & 0 & $4.38 \times 10^{-3}$ \\
\hline 30 & $\mathrm{~L}_{8}$ & 0.03593 & 0 & $2.07 \times 10^{-3}$ & 0 \\
\hline 31 & $\mathrm{H}_{5}$ & 0 & 0.4404 & 0 & $1.74 \times 10^{-2}$ \\
\hline 32 & $\mathrm{RD}_{1}$ & 0 & 0.3491 & 0 & $7.72 \times 10^{-3}$ \\
\hline 33 & $\mathrm{H}_{5}, \mathrm{~L}_{1}$ & 0.06931 & 0.9742 & $4.88 \times 10^{-3}$ & $2.88 \times 10^{-2}$ \\
\hline 34 & $\mathrm{~L}_{5}$ & 0.0682 & 0 & $3.52 \times 10^{-3}$ & 0 \\
\hline 35 & $\mathrm{~L}_{8}$ & 0.0392 & 0 & $2.74 \times 10^{-3}$ & 0 \\
\hline 36 & $\mathrm{~L}_{8}$ & 0.1667 & 0 & $6.61 \times 10^{-3}$ & 0 \\
\hline 37 & $\mathrm{~L}_{4}, \mathrm{LD}_{4}$ & 0.1179 & 0.1747 & $7.24 \times 10^{-3}$ & $6.17 \times 10^{-3}$ \\
\hline 38 & $\mathrm{~L}_{1}$ & 0.0788 & 0 & $7.47 \times 10^{-3}$ & 0 \\
\hline 39 & $\mathrm{~L}_{4}, \mathrm{H}_{1}$ & 0.0419 & 0.1766 & $4.46 \times 10^{-3}$ & $8.74 \times 10^{-3}$ \\
\hline 40 & $\mathrm{~L}_{5}$ & 0.0858 & 0 & $3.31 \times 10^{-3}$ & 0 \\
\hline 41 & $\mathrm{~L}_{1}$ & 0.0374 & 0 & $2.92 \times 10^{-3}$ & 0 \\
\hline \multirow{2}{*}{42} & $\mathrm{~L}_{1}, \mathrm{H}_{1}$ & 0.3441 & 0.7682 & $2.04 \times 10^{-2}$ & $3.71 \times 10^{-2}$ \\
\hline & $\mathrm{LD}_{1}$ & 0 & 0.3523 & 0 & $1.30 \times 10^{-2}$ \\
\hline \multirow{2}{*}{43} & $\mathrm{H}_{5}$ & 0 & 0.2990 & 0 & $7.88 \times 10^{-3}$ \\
\hline & $\mathrm{RD}_{5}$ & 0 & 0.2499 & 0 & $4.66 \times 10^{-3}$ \\
\hline 44 & $\mathrm{~L}_{4}$ & 0.1292 & 0 & $6.34 \times 10^{-3}$ & 0 \\
\hline 45 & $\mathrm{~L}_{4}$ & 0.0668 & 0 & $4.67 \times 10^{-3}$ & 0 \\
\hline
\end{tabular}




\begin{tabular}{llllll}
\hline 46 & $\mathrm{H}_{5}$ & 0 & 0.3194 & 0 & $1.44 \times 10^{-2}$ \\
47 & $\mathrm{~L}_{8}$ & 0.2849 & 0 & $9.03 \times 10^{-3}$ & 0 \\
48 & $\mathrm{~L}_{5}$ & 0.1013 & 0 & $4.28 \times 10^{-3}$ & 0 \\
49 & $\mathrm{LD}_{1}$ & 0 & 0.5502 & 0 & $1.21 \times 10^{-2}$ \\
50 & $\mathrm{~L}_{4}, \mathrm{H}_{5}$ & 0.0526 & 0.1809 & $4.42 \times 10^{-3}$ & $6.50 \times 10^{-3}$ \\
\hline
\end{tabular}

\section{References}

[1] Paik JK. Advanced structural safety studies with extreme conditions and accidents. Singapore: Springer; 2019.

[2] ABS. Guidance notes on accidental load analysis and design for offshore structures. Houston, TX: 2013.

[3] Bentley. Structural integrity assessment of a ship-impacted wellhead platform 2017.https://www.bentley.com/en/project-profiles/zakum_development_compa ny_wellhead_platform (accessed April 28, 2019).

[4] PSA. Investigation of Big Orange XVIII's collision with Ekofisk 2/4-W. The Petroleum Safety Authority Norway. 2009.

[5] Daley J. Mumbai High North platform disaster. Coast Ocean Eng Undergrad Student Forum 2013:1-8.

[6] NORSOK. Actions and action effects: N-003. 3rd ed. Lyasker, Norway: 2017.

[7] NORSOK. Z-013 Risk and emergency preparedness assessment. 3rd ed. Lysaker, Norway: 2010.

[8] Lloyd's Register. Guidance notes for risk based analysis: collisions. London, UK: Lloyd's Register Group Limited; 2014.

[9] HSE. Effective collision risk management for offshore installations: Offshore Technology Report OTO 1999 052. 2000.

[10] CMPT. A guide to quantitative risk assessment for offshore installations. 1999.

[11] Mujeeb-Ahmed MP, Seo JK, Paik JK. Probabilistic approach for collision risk analysis of powered vessel with offshore platforms. Ocean Eng 2018;151:20621.

[12] Mujeeb-Ahmed MP, Paik JK. A probabilistic approach to determine design loads for collision between an offshore supply vessel and offshore installations. Ocean Eng 2019;173:358-74.

[13] Mujeeb-Ahmed MP, Ince ST, Paik JK. Computational models for the structural crashworthiness analysis of a fixed-type offshore platform in collisions with an offshore supply vessel. Thin-Walled Struct 2020;154.

[14] API. Interim guidance on hurricane conditions in the Gulf of Mexico. API 2INT-MET. Washington, DC: API Publishing Services; 2007.

[15] DNV GL. Recommended practice, DNVGL-RP-C205, Environmental conditions and environmental loads 2017.

[16] Hallquist JO. LS-DYNA keyword user's manual. Livermore Softw Technol Corp 2007;970:299-800.

[17] Cowper GR, Symonds PS. Strain-hardening and strain-rate effects in the 
impact loading of cantilever beams. Division of Applied Mathematics. Brown University: 1957.

[18] Jones N. On the dynamic inelastic failure of beams. In: Wierzbicki T, Jones N, editors. Struct. Fail., John Wiley; 1989, p. 133-59.

[19] Paik JK. Practical techniques for finite element modeling to simulate structural crashworthiness in ship collisions and grounding (Part I: Theory). Ships Offshore Struct 2007;2:1:69-80.

[20] Paik JK. Practical techniques for finite element modelling to simulate structural crashworthiness in ship collisions and grounding (Part II : Verification). Ships Offshore Struct 2007;2:1:81-5.

[21] Hughes OF, Paik JK, Béghin D, Caldwell JB, Payer HG, Schellin TE. Ship structural analysis and design. Jersey City: The Society of Naval Architects and Marine Engineers; 2010.

[22] Paik JK, Kim KJ, Lee JH, Jung BG, Kim SJ. Test database of the mechanical properties of mild, high-tensile and stainless steel and aluminium alloy associated with cold temperatures and strain rates. Ships Offshore Struct 2017;12:S230-56.

[23] Paik JK, Thayamballi AK. Ship-shaped offshore installations: design, building, and operation. Cambridge: Cambridge University Press; 2007.

[24] Storheim M, Amdahl J. On the sensitivity to work hardening and strain- rate effects in nonlinear FEM analysis of ship collisions. Ships Offshore Struct 2017;12(1):100-15.

[25] Ince ST, Kumar A, Paik JK. A new constitutive equation on ice materials. Ships Offshore Struct 2017;12:610-23.

[26] Liu K, Liu B, Villavicencio R, Wang Z, Guedes Soares C. Assessment of material strain rate effects on square steel plates under lateral dynamic impact loads. Ships Offshore Struct 2018;13:217-25.

[27] Ko YG, Kim SJ, Sohn JM, Paik JK. A practical method to determine the dynamic fracture strain for the nonlinear finite element analysis of structural crashworthiness in ship-ship collisions. Ships Offshore Struct 2018;13(14):412-22.

[28] Ferry M, Le Sourne H, Besnier F. 02/RT016: MCOL theoretical manual. Principia Tech Rep 2002:1-18.

[29] Ferry M, Le Sourne H, Besnier F. 02/RT017: MCOL user's manual. Principia Tech Rep 2002:1-15.

[30] API. Recommended practice 2A-WSD: planning, designing and constructing fixed offshore platforms - working stress design. 22nd ed. Washington, DC: American Petroleum Institute; 2014.

[31] Harwood RG, Shuttleworth EP. Grouted and mechanical strengthening repair of tubular steel offshore structures. Department of Energy, Offshore Technology Report, OTH 88 283. London, UK: 1988.

[32] El-Reedy MA. Assessment of existing structures and repairs. Offshore Struct. Des. Constr. Maint. 1st ed., Gulf Professional Publishing; 2012, p. 445-561.

[33] Sveen D. Oseberg B Jacket-damage assessment and repair after submarine 
collision. J Pet Technol 1990;42:1421-5.

[34] Gerwick BC. Repairs to marine structures. Constr. Mar. offshore Struct. 3rd ed., California, USA: Taylor \& Francis Group; 2007, p. 643-58.

[35] Cabrera-Miranda JM, Sakugawa PM, Corona-Tapia R, Paik JK. On design criteria for a disconnectable FPSO mooring system associated with expected life-cycle cost. Ships Offshore Struct 2018;13(4):434-42.

[36] Turan O, Ölçer Aİ, Lazakis I, Rigo P, Caprace JD. Maintenance/repair and production-oriented life cycle cost/earning model for ship structural optimisation during conceptual design stage. Ships Offshore Struct 2009;4(2):107-25.

[37] Eldin MN, Kim J. Sensitivity analysis on seismic life-cycle cost of a fixed-steel offshore platform structure. Ocean Eng 2016;121:323-40.

[38] Paik JK, Kim SJ, Ko YG, Youssef SAM. Collision risk assessment of a VLCC class tanker. Houston: 2017.

[39] Project Controls International. Offshore oil and gas fabrication costs (productivity and complexity/ West Africa vs. Korea). Offshore Fabr Costs 2011.

[40] DNV GL. Marine risk assessment: Offshore Technology Report 2001/063. HSE Books; 2002.

[41] Kim YS, Youssef S, Ince S, Kim SJ, Seo JK, Kim BJ, Paik JK. Environmental consequences associated with collisions involving double hull oil tanker. Ships Offshore Struct 2015;10:479-87.

[42] Youssef SAM, Faisal M, Seo JK, Kim BJ, Ha YC, Kim DK, Paik JK. Assessing the risk of ship hull collapse due to collision. Ships Offshore Struct 2016;11:335-50. https://doi.org/10.1080/17445302.2014.993110.

[43] DNV GL AS. Offshore standards DNVGL-OS-C101 Design of Offshore Steel Structures, General - LRFD Method. Høvik, Norway: 2018.

[44] Moan T. Development of accidental collapse limit state criteria for offshore structures. Struct Saf 2009;31:124-35.

[45] HSE. Loads: Offshore Technology Report OTO 2001/013. HSE Books; 2002.

[46] Canada Oil and Gas Installations Regulations. SOR/96-118, Canda oil and gas operations act. Minister of Justice; 2016.

[47] API. Recommended practice 2A-WSD: planning, designing and constructing fixed offshore platforms - working stress design. 9th ed. American Petroleum Institute 1977.

[48] DNV GL AS. 2015-0984, FE model library for collision analysis: description and results. Høvik, Norway: 2016.

[49] Belytschko T, Lin JI, Chen-Shyh T. Explicit algorithms for the nonlinear dynamics of shells. Comput Methods Appl Mech Eng 1984;42:225-51.

[50] Yang KH. Meshing, element types, and element shape functions. Basic Finite Elem. Method as Appl. to Inj. Biomech., London, UK: Elsevier; 2018, p. 51109.

[51] Sohn JM, Bae DM, Bae SY, Paik JK. Nonlinear structural behaviour of membrane-type LNG carrier cargo containment systems under impact pressure 
loads at $-163{ }^{\circ} \mathrm{C}$. Ships Offshore Struct 2017;12:722-33.

[52] Paik JK. Ultimate limit state analysis and design of plated structures. 2nd ed. Chichester, UK: 2018.

[53] Storheim M, Amdahl J. Design of offshore structures against accidental ship collisions. Mar Struct 2014;37:135-72.

[54] Pill I, Tabri K. Finite element simulations of ship collisions: A coupled approach to external dynamics and inner mechanics. Ships Offshore Struct 2011;6:59-66.

[55] Rudan S, Ćatipović I, Berg R, Völkner S, Prebeg P. Numerical study on the consequences of different ship collision modelling techniques. Ships Offshore Struct 2019;14:387-400.

[56] Yu Z, Liu Z, Amdahl J. Discussion of assumptions behind the external dynamic models in ship collisions and groundings. Ships Offshore Struct 2019;14:4562.

[57] Tabri K. Influence of coupling in the prediction of ship collision damage. Ships Offshore Struct 2012;7(1):47-54.

[58] Pedersen PT, Zhang S. On impact mechanics in ship collisions. Mar Struct 1999;11(10):429-49.

[59] Ko YG, Kim SJ, Paik JK. Effects of a deformable striking ship's bow on the structural crashworthiness in ship-ship collisions. Ships Offshore Struct 2018;13:sup1:228-50.

[60] Zheng Y, Aksu S, Vassalos D, Tuzcu C. Study on side structure resistance to ship-ship collisions. Ships Offshore Struct 2007;2:273-93.

[61] Liu B, Villavicencio R, Zhang S, Guedes Soares C. Assessment of external dynamics and internal mechanics in ship collisions. Ocean Eng 2017;141:32636.

[62] Ehlers S, Guiard M, Kubiczek J, Höderath A, Sander F, Sopper R, et al. Experimental and numerical analysis of a membrane cargo containment system for liquefied natural gas. Ships Offshore Struct 2017;12:S257-67.

[63] Storheim M, Amdahl J, Martens I. On the accuracy of fracture estimation in collision analysis of ship and offshore structures. Mar Struct 2015;44:254-87.

[64] Zhang S, Pedersen PT, Villavicencio R. Probability and mechanics of ship collision and grounding. Oxford, UK: Butterworth-Heinemann, Elsevier; 2019.

[65] DNV GL. Recommended practice, DNVGL-RP-C204, Design against accidental loads. Høvik, Norway: 2017.

[66] Cho S, Kwon J, Kwak D. Structural characteristics of damaged offshore tubular members. Ocean Eng Technol 2010;24:1-7.

[67] Furnes O, Amdahl J. Ship collisions with offshore platforms. Intermaritec, Hamburg, Germany: 1980, p. 310-8.

[68] Ellinas CP, Walker AC. Damage on offshore tubular bracing members. IABSE 1983:253-61.

[69] Wierzbicki T, Suh MS. Indentation of tubes under combined loading. Int J Mech Sci 1988;30:229-48.

[70] HSE. Ship collision and capacity of brace members of fixed steel offshore 
platforms: Research Report 220. HSE Books; 2004. 